\title{
Role of the Dorsal Medial Habenula in the Regulation of Voluntary Activity, Motor Function, Hedonic State, and Primary Reinforcement
}

\author{
Yun-Wei A. Hsu, ${ }^{1}$ Si D. Wang, ${ }^{1}$ Shirong Wang, ${ }^{2}{ }^{\circledR}$ Glenn Morton, ${ }^{1}$ Hatim A. Zariwala, ${ }^{1}$ Horacio 0. de la Iglesia, ${ }^{3}$ \\ and (D)Eric E. Turner ${ }^{1,4,5}$ \\ ${ }^{1}$ Center for Integrative Brain Research, Seattle Children's Research Institute, Seattle, Washington 98101, ${ }^{2}$ Sanford-Burnham Medical Research Institute, La \\ Jolla, California 92037, ${ }^{3}$ Department of Biology, University of Washington, Seattle, Washington 98195-1800, ${ }^{4}$ Department of Psychiatry and Behavioral \\ Sciences, University of Washington, Seattle, Washington 98195, and ${ }^{5}$ Center on Human Development and Disability, University of Washington, Seattle, \\ Washington 98195
}

The habenular complex in the epithalamus consists of distinct regions with diverse neuronal populations. Past studies have suggested a role for the habenula in voluntary exercise motivation and reinforcement of intracranial self-stimulation but have not assigned these effects to specific habenula subnuclei. Here, we have developed a genetic model in which neurons of the dorsal medial habenula ( $\mathrm{dMHb}$ ) are developmentally eliminated, via tissue-specific deletion of the transcription factor Pou4f1 (Brn3a). Mice with dMHb lesions perform poorly in motivation-based locomotor behaviors, such as voluntary wheel running and the accelerating rotarod, but show only minor abnormalities in gait and balance and exhibit normal levels of basal locomotion. These mice also show deficits in sucrose preference, but not in the forced swim test, two measures of depression-related phenotypes in rodents. We have also used Cre recombinase-mediated expression of channelrhodopsin-2 and halorhodopsin to activate dMHb neurons or silence their output in freely moving mice, respectively. Optical activation of the $\mathrm{dMHb}$ in vivo supports intracranial self-stimulation, showing that dMHb activity is intrinsically reinforcing, whereas optical silencing of dMHb outputs is aversive. Together, our findings demonstrate that the dMHb is involved in exercise motivation and the regulation of hedonic state, and is part of an intrinsic reinforcement circuit.

Key words: exercise motivation; interpeduncular nucleus; intracranial self-stimulation; medial habenula; optogenetics

\section{Introduction}

Changes in physical activity and the inability to enjoy rewarding or pleasurable experiences (anhedonia) are two of the hallmarks of major depression. Conversely, structured exercise is one of the best-documented nonpharmacological interventions for depressed mood (Trivedi et al., 2011). Consistent with this, rodents have a strong drive to engage in voluntary wheel running activity (WRA) (Novak et al., 2012), and access to a running wheel re-

\footnotetext{
Received May 2, 2014; revised July 2, 2014; accepted July 7, 2014

Author contributions:Y.-W.A.H., S.D.W., S.W., H.A.Z., H.O.d.I.I., and E.E.T. designed research; Y.-W.A.H., S.D.W., S.W., G.M., and H.A.Z. performed research; Y.-W.A.H., S.D.W., G.M., H.A.Z., H.O.d.I.I, and E.E.T. analyzed data; Y.-W.A.H., S.D.W., G.M., and E.E.T. wrote the paper.

This work was supported by National Institute of Mental Health Awards R21 MH090478 and R01 MH093667 to E.E.T., National Science Foundation IOS-1145796 to H.O.d.I.I., and National Institute of Child Health and Human Development Award P3OHD02274 to the Center on Human Development and Disability. Y.-W.A.H. was supported by the National Institute of Mental Health Training Award F32MH098498. We thank Dr. Toby Cole at the Center on Human Development and Disability Mouse Behavior Core for providing behavioral testing equipment and guidance, Dr. Susan Ferguson for extensive advice on behavioral models, Drs. Ben Greenwood and Elizabeth Glenn Guy for helpful comments on the experimental results and manuscript, and Lynne Tempest and Lely Quina for technical assistance. The content is solely the responsibility of the authors and does not necessarily represent the official views of the National Institutes of Health.

The authors declare no competing financial interests.

Correspondence should be addressed to Dr. Eric E. Turner, Seattle Children's Research Institute, 1900 Ninth Avenue, Mail Stop C9S-10, Seattle, WA 98101. E-mail: eric.turner@seattlechildrens.org.

DOI:10.1523/JNEUROSCI.1861-14.2014

Copyright $\odot 2014$ the authors $\quad 0270-6474 / 14 / 3411366-19 \$ 15.00 / 0$
}

lieves behavioral states induced by acute and chronic stress that resemble human depression (Solberg et al., 1999; Greenwood et al., 2003; Duman et al., 2008). However, the neural pathways underlying exercise motivation and the maintenance of mood states are not well understood.

The medial habenula ( $\mathrm{MHb})$ is a paired midline structure located on the dorsal surface of the thalamus (epithalamus). Past studies using electrical stimulation, or using lesions of the habenula or its output tract, have assigned a variety of behavioral functions to this region, including primary reinforcement (Klemm, 2004; Lecourtier and Kelly, 2007). However, most of these studies have not distinguished the $\mathrm{MHb}$ from the adjacent lateral habenula, which is known to mediate negative motivational values, including reward prediction error and punishment (Jhou et al., 2009; Hong et al., 2011).

$\mathrm{MHb}$ neurons are glutamatergic, but two principal subnuclei can be identified by the use of acetylcholine as a cotransmitter in the ventral $\mathrm{MHb}(\mathrm{vMHb})$ and the expression of the neuropeptide substance $\mathrm{P}(\mathrm{SP})$ in the dorsal MHb (dMHb) (Contestabile et al., 1987; Lecourtier and Kelly, 2007; Ren et al., 2011). In addition, although the $\mathrm{dMHb}$ and $\mathrm{vMHb}$ project to the same region of the ventral midbrain, the interpeduncular nucleus (IP), they innervate distinct structures there (Quina et al., 2009; Hsu et al., 2013). Recent work has suggested a role for the cholinergic neurons of 
the vMHb in behavioral responses to nicotine (Grady et al., 2009; Salas et al., 2009; Görlich et al., 2013; Leslie et al., 2013). In contrast, no specific function has been assigned to the dMHb.

In the present study, we have investigated the behavioral functions of the $\mathrm{dMHb}$ using three mouse models: a developmental genetic lesion mediated by loss of function of the transcription factor Pou $4 \mathrm{fl}$ (Brn3a) that specifically ablates the $\mathrm{dMHb}$; the Cremediated conditional expression of channelrhodopsin $\left(\mathrm{ChR} 2{ }^{\mathrm{H} 134 \mathrm{R}}\right)$ in the $\mathrm{dMHb}$, allowing the specific activation of this region with light; and conditional expression of halorhodopsin (eNpHR3.0) in the $\mathrm{dMHb}$, allowing the silencing of the output of this nucleus to the IP. Ablation of the $\mathrm{dMHb}$ reduces voluntary WRA with relatively little effect on simple tests of gait and balance and no effect on basal locomotion, and also reduces sucrose preference, a measure of hedonic state. Consistent with a role for the $\mathrm{dMHb}$ in mediating positive mood states, optogenetic stimulation of the $\mathrm{dMHb}$ is strongly reinforcing in an intracranial selfstimulation (ICSS) paradigm. Conversely, optogenetic silencing of $\mathrm{dMHb}$ output to the IP produces acute place aversion. Collectively, our data suggest that the $\mathrm{dMHb}$ is part of a pathway required to motivate voluntary exercise and regulate hedonic state, and that $\mathrm{dMHb}$ activity can mediate primary reinforcement.

\section{Materials and Methods}

Generation of transgenic mice. For Cre-mediated disruption of the Pou4f1 gene, mice were generated containing loxP sites flanking Pou4f1 exon 2 ("floxed" allele), which contains most of the Brn3a protein-coding sequence, including the DNA-binding domain. ES cell targeting was performed in 129 ES cells using a congenic targeting construct introducing the loxP sites and a TK-NEO selection cassette (see Fig. 1A). Correct targeting of the locus was demonstrated in the primary screen of recombinant ES cell clones by PCR across the 3' targeting arm and confirmed by Southern blotting using an introduced Hind 3 restriction site and a probe derived from the $5^{\prime}$ targeting arm. ES cells were injected into C57BL/6 blastocysts to generate chimeric founders, which were screened for germline transmission of the floxed allele. Transgenic services were provided by the University of California San Diego Transgenic Core Facility. Germ-line excision of the TK-NEO cassette in the chosen founder line was performed by crossing with mice bearing FLPeR allele, expressed from the Rosa26 locus (Farley et al., 2000), to generate the allele Pou $4 f^{\text {flox }}$.

The Syt6-BAC Cre transgenic line $\left(S y t 6^{\mathrm{Cre}}\right)$ from the Gensat project, STOCK Tg(Syt6-Cre)KI148Gsat/Mmcd, was used for the manipulation of loxP-mediated transgenic events in the $\mathrm{dMHb}$. The Syt $6^{\mathrm{Cre}}$ transgenic line was obtained as cryopreserved sperm from the Mutant Mouse Regional Resource Center of the University of California, Davis, and recovered by in vitro fertilization of C57BL/6 mouse oocytes by the University of Washington Transgenic Resources Program. Both the Pou $4 f^{f l o x}$ and Syt $6^{\text {Cre }}$ mice were backcrossed $>6$ generations to C57BL/6NCrl mice (Charles River Laboratories) before use in behavioral experiments with the exception of FST, where the Syt ${ }^{C r e}$ mice were backcrossed for 4 generations to C57BL/6 mice. To generate mice with a tissue-specific null mutation of Pou4f1 in the $\mathrm{dMHb}, S y t 6^{\mathrm{Cre}}$ mice were first interbred with a mouse strain containing a Pou $4 f 1$ targeted tauLacZ transgene, consisting of a fusion of bovine tau with Escherichia coli lacZ (Quina et al., 2005), to generate mice with the genotype Pou $4 \mathrm{fl}^{\text {tlacZ/+}}$, Syt $6^{\mathrm{Cre} /+}$. Pou $4 \mathrm{fl}^{\text {tlac }}$ is also a null allele of Pou4f1. These mice were then backcrossed to Syt $6^{\mathrm{Cre} /+}$ animals to generate homozygous Cre driver mice with the genotype Pou4f1 $1^{\text {tlacZ/+ }}$, Syt6 ${ }^{\mathrm{Cr} / \mathrm{Cre}}$. These mice were then interbred with Pou $4 f_{1} 1^{\text {flox/flox }}$ mice to yield the genotypes Pou4f1 $1^{\text {tlacZ/flox }}$, Syt $6^{\text {Crel+ }}\left(\mathrm{dMHb}^{\mathrm{CKO}}\right)$ and Pou $4 \mathrm{f}^{\text {flox/+ }}$, Syt6 $6^{\text {Cre/+ }}$ (control) mice in equal ratios. The initial characterization of the $\mathrm{dMHb}$ genetic lesion model was examined in control mice, with the genotype of Pou $4 f_{1} 1^{\text {flox/tlac } Z}$, and $\mathrm{dMHb}{ }^{\mathrm{CKO}}$ mice, with the genotype of Pou4ff $1^{\text {flox/tlac } Z \text {, }}$ Syt $6^{\mathrm{Cre} /+}$ to allow immunofluorescent detection of the lacZ gene product, $\beta$-galactosidase, in both $\mathrm{dMHb}^{\mathrm{CKO}}$ mice and control mice.

The mouse strains used for Cre-inducible expression of Channelrhodopsin2 (Ai32, expressing ChR2(H134R)-YFP) and Halorhodopsin
(Ai39, expressing eNpHR3.0-EYFP) have been described (Madisen et al., 2012). Both strains express their respective fusion proteins from a modified floxed-stop Gt(Rosa) $26^{\text {Sor }}$ locus. Ai32 mice were interbred with Syt $6^{\text {Cre }}$ mice to yield the double-heterozygous Ai32, Syt $6^{\mathrm{Cre}}\left(\mathrm{dMHb}^{\mathrm{ChR} 2}\right)$ optogenetic mice used for activation of the $\mathrm{dMHb}$. Ai39 mice were interbred with Syt6 ${ }^{\text {Cre }}$ mice to yield double-heterozygous Ai39, Syt6 ${ }^{\text {Cre }}$ $\left(\mathrm{dMHb}{ }^{\mathrm{NpHR}}\right)$ optogenetic mice used for silencing of $\mathrm{dMHb}$ efferents. Control mice for the optogenetic studies were derived from the same crosses but lacked either the opsin allele or the cre-driver allele. All mouse lines were maintained on a $\mathrm{C} 57 \mathrm{BL} / 6 \mathrm{NCrl}$ genetic background. Behavioral assays were performed on male mice 2-8 months of age.

Genotyping. Genotyping was performed by real-time PCR using the following oligonucleotide pairs: Cre allele, forward, TGGGCCAGCTA AACATGCTT; reverse, AACAGCATTGCTGTCACTTGGT; Rosa26 locus common primer, forward, TCGTGATCTGCAACTCCAGTCTT; Ai32 allele specific primer, reverse, TGGGCTATGAACTAATGACCCC; Rosa26 WT locus specific primer, reverse, CGCCCACACACCAGGT TAG; Ai39 allele specific primers, forward, CGTGCTGAACGACCC TTTG; reverse, CCTGCAAGTGCGATGTTGAT; Pou4f1 flox gene, forward, TACGAAGTTATTAGGTCCCTCG; reverse, GCAGAGTGG AGCTGAGGGAA; Pou4f1 WT gene, forward, CGCAGCGTGAGAAA ATGA AC; reverse, CGATGGAAGTCCGCTTGC; tauLacZ transgene, forward, GAGGAACCAGGCTCTGAAACC; reverse, AAGGGTGCTG TCGCATCTTC.

Immunohistochemistry and in situ hybridization (ISH). Adult mice were injected intraperitoneally with pentobarbital $(120 \mathrm{mg} / \mathrm{kg})$ and then perfused transcardially with PBS followed by $4 \%$ PFA in PBS. Brains were fixed in $4 \%$ PFA in PBS at room temperature for $4 \mathrm{~h}$ while shaking, equilibrated in $15 \%$ then $30 \%$ sucrose, embedded in OCT medium, and cryo-sectioned at $30 \mu \mathrm{m}$ for both immunohistochemistry and ISH. Primary antibodies used included the following: guinea pig anti-Brn3a (Quina et al., 2005), goat anti-ChAT (Millipore), and rabbit anti- $\beta$ galactosidase ( $\beta$-Gal; 5Prime-3Prime). Secondary antibodies conjugated to Alexa series fluorophores were obtained from Invitrogen. ISH methods and sources of ISH probes have been previously described (Eng et al., 2004; Quina et al., 2009).

The full extent of the $\mathrm{dMHb}$ lesion in $\mathrm{dMHb}^{\mathrm{CKO}}$ mice compared with controls was examined by immunofluorescent labeling of alternate sections for Brn3a plus ChAT and $\beta$-gal $\left(\right.$ Pou $\left.4 f_{1}{ }^{\text {tlac }}\right)$ plus ChAT in coronal sections at $120 \mu \mathrm{m}$ intervals from bregma $-0.98 \mathrm{~mm}$ to $-2.06 \mathrm{~mm}$, which encompass the extent of the habenula as identified in a standard atlas (Paxinos and Franklin, 2001). The Pou4f1 ${ }^{\text {tlac } Z}$ allele, in which a lac $Z$ transgene replaces the Brn3a coding sequence, allowed the use of $\beta$-gal expression to identify any remaining neurons in the $\mathrm{dMHb}$ of $\mathrm{dMHb}$ CKO mice that may not express Brn3a protein due to Pou $4 \mathrm{fl}$ excision. The area of expression of ${\mathrm{Brn} 3 \mathrm{a}^{+}}^{+}$(control) and $\beta$-gal ${ }^{+}\left(\mathrm{dMHb}^{\mathrm{CKO}}\right)$ in the right and left $\mathrm{dMHb}$ was measured using Image . ChAT immunostaining was used to demarcate the boundary between $\mathrm{dMHb}$ and $\mathrm{vMHb}$. The extent of the genetic $\mathrm{dMHb}$ lesion was also examined in the large behavioral cohort of mice used in the WRA, open field, PhenoTyper cages, CatWalk, rotarod, and sucrose preference tests. Two habenular sections $(30 \mu \mathrm{m}$ sections at bregma -1.6 and $-1.9 \mathrm{~mm}$ ) from the $\mathrm{dMHb}^{\mathrm{CKO}}$, and control mice were immunostained for Brn3a, $\beta$-gal, and ChAT and analyzed for the area of the $\mathrm{dMHb}$. The $\mathrm{dMHb}{ }^{\mathrm{CKO}}$ mice showed significant reductions in both the rostral and caudal sections compared with the control mice. Little variation was observed in the small remaining area of the $\mathrm{dMHb}$, and there was no correlation between the extent of the lesion and the behavioral outcomes.

Behavioral analysis of $\mathrm{dMH} \mathrm{b}^{\mathrm{CKO}}$ mice. Behavioral analysis was performed on $\mathrm{dMHb}{ }^{\mathrm{CKO}}$ mice (Pou4f1 $1^{\text {tlacZ/flox }}$, Syt $\left.6^{\mathrm{Cre} /+}\right)$ and their control littermates $\left(\right.$ Pou $4 f 1^{\text {flox/+ }}$, Syt6 $\left.\mathrm{Cre} /+^{\mathrm{C}}\right)$. All tests were conducted using male mice between 2 and 8 months of age. Three large cohorts of control and $\mathrm{dMHb}{ }^{\mathrm{CKO}}$ mice were used for preliminary and reported experiments. In Figures 3, 4, and 5, the data reported were obtained from a single cohort of mice, except for the forced swim test (FST), which was performed on a different cohort. For the main cohort, the order of the tests performed was as follows: Sucrose preference test, accelerating rotarod, home cage locomotion, CatWalk gait analysis, open field locomotion, and WRA. Wheel running was performed last such that the differential running of 
the control and $\mathrm{dMHb}^{\mathrm{CKO}}$ mice would not impact the other tests. Mice were housed on a 12:12 light and dark (LD) cycle with lights off at 7 PM.

WRA. Mice were individually housed in cages equipped with a running wheel and maintained in a ventilated, light-tight chamber under a 12:12 LD cycle with 200-lux intensity. WRAs were monitored using Clocklab software (Actimetrics) and analyzed using the El Temps software (Han et al., 2012). Data were analyzed in $10 \mathrm{~min}$ or $60 \mathrm{~min}$ bins for doubleplotted WRA actograms or WRA waveform, respectively.

Accelerating rotarod. The Rotamex-5 (Columbus Instruments) was used to test rotarod performance. The apparatus is fitted with a $7.0-\mathrm{cm}-$ diameter dowel with a fall height of $44.5 \mathrm{~cm}$ from the dowel center. Before testing, all mice were trained on a fixed-speed protocol at $4 \mathrm{rpm}$ until they could stay on the rod for $30 \mathrm{~s}$ ( $4-7$ trials). On the same day as the training sessions, mice underwent four $5 \mathrm{~min}$ accelerating rotarod trials. In each trial, the rotarod accelerated from 4 to $40 \mathrm{rpm}$ at the rate of $1 \mathrm{rpm}$ every $8 \mathrm{~s}$, then remained at $40 \mathrm{rpm}$ until the end of the trial. The principal outcome was the time (latency) until the mouse fell from the rod. Mice were given at least $15 \mathrm{~min}$ of rest in between each trial. A second session of four trials was performed the following day to determine the reproducibility of the test. No training period was conducted on the second day of testing. To calculate the average latency to fall for each mouse, the lowest of four values was discarded.

Open field locomotion. The open field enclosure consists of a $27.3 \mathrm{~cm} \times$ $27.3 \mathrm{~cm}$ arena (ENV-510, Med Associates) housed in a sound attenuating chamber (ENV-018MD, Med Associates). Mice were recorded by an Ikegami ICD-49 B/W video camera with heliopan E35.5 RG 850 IR lens filter (Ikegami Tsushinki) lit by an IR Illuminator (YY-IR30, YY Trade) for $30 \mathrm{~min}$. For determination of time spent in the center and periphery of the enclosure, a center area of $17.5 \times 17.5 \mathrm{~cm}$ was defined in the video image. The total distance traveled was analyzed using the video-tracking software, EthoVision XT 8.5 (Noldus Information Technology).

PhenoTyper home cages. The PhenoTyper home cage (model 3000, floor dimensions: $30 \times 30 \mathrm{~cm}$, Noldus Information Technology) is equipped with food, water, and a flat-topped, triangular floor shelter with two entry holes that fits in one corner of the cage. The top unit is equipped with LED units and an IR camera so that the mice can be monitored undisturbed during both the light and dark cycles for several days. The mice were individually housed in the cages, and activities were recorded and tracked by EthoVision XT 8.5 for $3 \mathrm{~d}$. Activities on the third day were analyzed after $2 \mathrm{~d}$ of habituation in the cages.

CatWalk automated gait analysis. The CatWalk (Noldus Information Technology) is a proprietary apparatus for assessing small animal gait (Gabriel et al., 2007). The walking platform consists of a transilluminated glass floor $(100 \mathrm{~cm} \times 12 \mathrm{~cm} \times 0.6 \mathrm{~cm})$ fitted with a portcullis at both ends that prevents the mouse from leaving the walkway. Internal reflection inside the glass walkway contains the light, except at points where an object touches the glass, where the light exits, scatters, and illuminates the contact area with intensity depending on the pressure exerted. These areas of contact are video recorded while mice traverse the walkway, and the video is analyzed using proprietary software (CatWalk XT 9.1, Noldus Information Technology), which assigns and categorizes each point of contact as right/left and fore/hindpaw, allowing the footfalls and gait to be assessed quantitatively. The points of contact are also examined by the investigator and corrected manually if necessary. The experiment was performed using the manufacturer's recommended CatWalk parameters, including a threshold value for skin-floor contact of 0.10 and video camera gain of $14.72 \mathrm{db}$. Each individual mouse had to remain on the walkway until three successful trials with a maximum variance in speed of $60 \%$ and maximum run duration of $6.0 \mathrm{~s}$ were achieved.

Balance beam test. The balance beam apparatus consisted of two platforms, 4 inch square, placed 18 inches apart, with the starting platform elevated 4 inches above the base of the apparatus and the ending platform elevated 8 inches. A dark plastic enclosure ("safe box") was placed on the 8 inch ending platform. The platforms were connected by a 1 inch square beam during training, and a series of graded round beams $(3 / 4,5 / 8,1 / 2$, and $3 / 8$ inch diameter) during actual testing. Testing was conducted in an enclosed hood under ambient room light. A video camera was placed behind the 4 inch starting platform but elevated slightly above the animal such that hindpaw faults could be easily recorded and the head of the

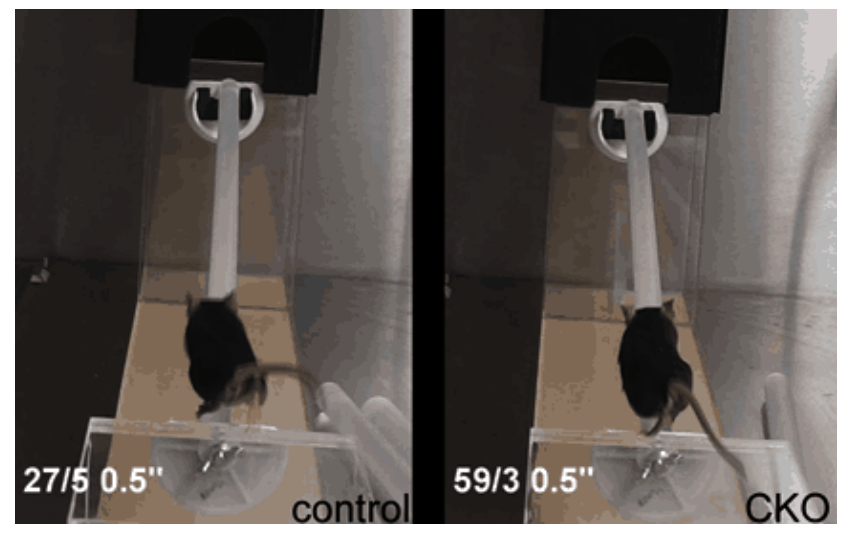

Movie 1. Balance beam performance of $\mathrm{dMHb}{ }^{\mathrm{CK} 0}$ and control mice. Movie 1 shows a contro (left) and $\mathrm{dMHb}^{\mathrm{CKO}}$ (right) mouse, each of which performed the balance beam task on a 0.5 inch bar without a fault. Movies are shown at actual speed. Although the performances of $\mathrm{dMHb}^{\mathrm{CKO}}$ and control mice could not be easily distinguished based on observation of single trials, the average run times for $\mathrm{dMHb}^{\mathrm{CKO}}$ are slightly slower, and $\mathrm{dMHb}^{\mathrm{CKO}}$ mice exhibit more faults.

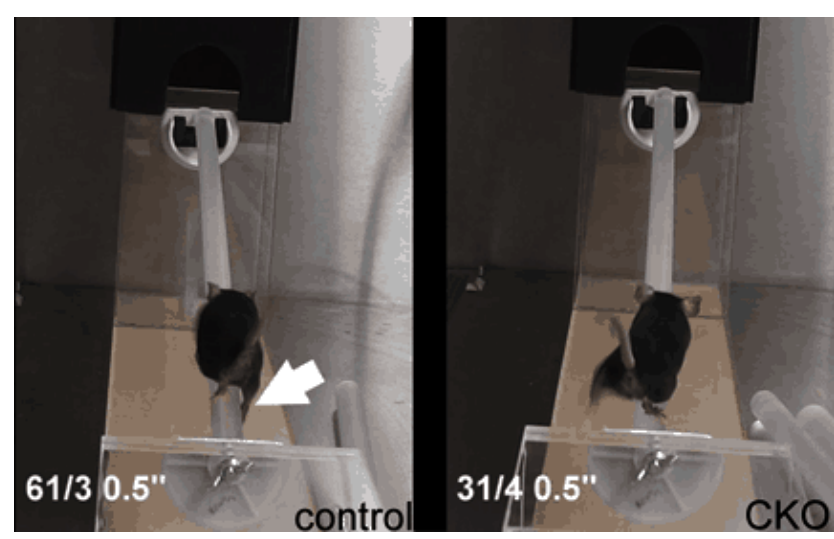

Movie 2. Balance beam performance of $\mathrm{dMHb}^{\mathrm{CK} 0}$ and control mice. Movie 2 shows a control (left) and $\mathrm{dMHb}^{\mathrm{CKO}}$ (right) mouse, each of which made a single fault during performance of the task (shown by brief appearance of an arrow). Movies are shown at actual speed. Although the performances of $\mathrm{dMHb}^{\mathrm{CKO}}$ and control mice could not be easily distinguished based on observation of single trials, the average run times for $\mathrm{dMHb}^{\mathrm{CKO}}$ are slightly slower, and $\mathrm{dMHb}^{\mathrm{CKO}}$ mice exhibit more faults.

animal was always visible (Movies 1 and 2). Preliminary examination from the side of the apparatus revealed that forepaw faults were rare, and these were not recorded.

Each mouse received five training sessions on the 1 inch square beam. During training, the mouse was given up to $1 \mathrm{~min}$ to explore the starting platform before being gently coaxed up and across the beam. After the mouse entered the safe box on the ending platform, it was given $30 \mathrm{~s}$ to rest inside before returning to the home cage. Cage mates were trained in rotation, through five iterations of training. On the testing day, each mouse was tested five times on each of the four graded beams, in descending order of size, using the same method as the training sessions. Balance beam performance was scored for beam transit time and the number of hindfoot faults observed (Brooks and Dunnett, 2009). Runs in which the mouse left or reversed direction on the bar were excluded as incomplete. The last three completed trials for each animal on a given diameter beam were used to compute the average transit time and the average number of faults for that subject.

Sucrose preference test. Mice were individually housed in their home cages equipped with two drinking bottles, one containing sucrose solution $(1 \%)$ and the other containing filtered tap water. Mice were first habituated to their new environment for $3 \mathrm{~d}$. Fluid consumption was measured over $4 \mathrm{~d}$ after the habituation period. Mice were allowed to drink freely between the two bottles during both the habituation and 
testing periods. Both bottles were weighed daily to measure fluid consumption, and the positions of the bottles were switched daily to prevent a side bias. Sucrose preference is calculated as the percentage of the amount of sucrose solution consumed over total fluid consumption [(sucrose solution intake/total fluid intake) $\times 100]$. A second test (including both the habituation and testing periods) was performed to determine reproducibility of the test. All mice were weighed at the end of the second test.

FST. Mice were individually placed in a $2 \mathrm{~L}$ Pyrex beaker filled with $\sim 12 \mathrm{~cm}$ of water $\left(30 \pm 1^{\circ} \mathrm{C}\right)$ so that they were not able to touch the bottom at any time and left to swim for $15 \mathrm{~min}$. The trials were recorded using a video camera from the side, and recordings were manually scored in $5 \mathrm{~s}$ bins for the predominant behavior. An animal was judged immobile when it was floating passively in the water and only making the necessary movements to keep the head above the water.

In vitro electrophysiology recordings. Electrophysiological studies of the $\mathrm{dMHb}$ were performed with $\mathrm{dMHb}{ }^{\mathrm{ChR} 2}$ mice of either sex between 4 and 8 weeks of age. For the preparation of acute brain slices used in loose-seal, cell-attached recording, adult mice were anesthetized with isoflurane, quickly decapitated, and the whole brains were dissected into cold aCSF containing the following (in $\mathrm{mm}$ ): $118 \mathrm{NaCl}, 3 \mathrm{KCl}, 25 \mathrm{NaHCO}_{3}, 1$ $\mathrm{NaH}_{2} \mathrm{PO}_{4}, 1 \mathrm{MgCl}_{2}, 1.5 \mathrm{CaCl}_{2}, 10$ glucose, $\mathrm{pH}$ 7.4. Coronal brain slices (300 or $350 \mu \mathrm{m}$ ) were cut with a vibratome (Leica VT1000S) in cold oxygenated aCSF, and slices were allowed to recover for at least $30 \mathrm{~min}$ at room temperature in oxygenated aCSF before transferring to the recording chamber. During recording slices were superfused with aCSF at $30^{\circ} \mathrm{C}$.

Loose-seal cell-attached recordings from $\mathrm{dMHb}$ neurons were obtained using blind-patch technique in slice preparations using brightfield optics to visualize the habenula. Recording electrodes (3-7 $\mathrm{m} \Omega$ ) were filled with $10 \mathrm{~mm}$ glucose aCSF, and recordings were obtained with a MultiClamp 700B Amplifier (Molecular Devices), connected to a digitizing interface (Digidata 1440), and analyzed with pClamp 10.2. Neurons expressing ChR2 in $\mathrm{dMHb}{ }^{\mathrm{ChR} 2}$ mice were identified based on the presence of light-induced action potentials. Optical stimulation of brain slice preparations to activate $\mathrm{ChR} 2$ was supplied by a $447 \mathrm{~nm}$ blue laser (OptoEngine) coupled to a $200 \mu \mathrm{m}, 0.22$ NA optical fiber (Thor Laboratories). The optical fiber was placed $5 \mathrm{~mm}$ from the habenula $(2.0$ $\mathrm{mW} / \mathrm{mm}^{2}$ ). Neurons expressing eNpHR3.0 in of $\mathrm{dMHb}{ }^{\mathrm{NpHR}}$ mice were identified based on light-induced inhibition of spontaneous action potentials. Optical stimulation to inhibit eNpHR3.0 was supplied by a 640 $\mathrm{nm}$ red laser (OptoEngine), and the optical fiber was placed $4 \mathrm{~mm}$ from the habenula $\left(46 \mathrm{~mW} / \mathrm{mm}^{2}\right)$.

$d M H b$ optogenetic stimulation studies. Optogenetic behavioral studies were performed with $\mathrm{dMHb}{ }^{\mathrm{ChR} 2}$ optogenetic mice and Syt6 ${ }^{\mathrm{Cre}}$ littermate controls. All tests were conducted using male mice between 4 and 7 months of age. Mice were implanted with a bilateral fiber optic cannula consisting of two $100 \mu \mathrm{m}, 0.22 \mathrm{NA}$ optical fibers (Thor Laboratories) that were spaced $0.7 \mathrm{~mm}$ apart and protruded $2.6-2.8 \mathrm{~mm}$ from a Delrin guide. The cannulas were placed at (bregma $-1.6 \mathrm{~mm}$ and $\pm 0.35 \mathrm{~mm}$ from the midline). The implanted optical fibers were connectorized with a single zirconia ferrule, linked in turn to a $200 \mu \mathrm{m}$ fiber optic patch cord (Thor Laboratories), an optical rotary joint (Doric Lenses), and a 100 $\mathrm{mW}, 473 \mathrm{~nm}$ DPSS laser (OptoEngine). Laser pulses were controlled by an optomechanical switch (Avantes) linked to a programmable microprocessor (Arduino, SparkFun Electronics). Duration and timing of the laser pulse trains were controlled and mouse body movements were tracked by EthoVision XT (Noldus Information Technology).

Optogenetic open field locomotion and ICSS of the $\mathrm{dMHb}$. Open field locomotion was performed in a $2.59 \mathrm{~cm} \mathrm{~L} \times 17.78 \mathrm{~cm} \mathrm{~W} \times 12.7 \mathrm{~cm} \mathrm{H}$ behavioral chamber with a $100 \mathrm{~mA}$ house light (Med Associates). Locomotor behavior was recorded, and the distance traveled was calculated using EthoVision XT. To avoid increased locomotion that may result from exposure to a novel environment, mice were habituated to the chamber before the test. The recorded session consisted of $20 \mathrm{~min}$ of baseline recording, followed by $10 \mathrm{~min}$ of intermittent laser stimulation, consisting of $30 \mathrm{~s}$ stimulation periods and $30 \mathrm{~s}$ laser off periods. Stimulation periods consisted of $25 \mathrm{~ms}, 20 \mathrm{~Hz}$ pulse trains, with a $473 \mathrm{~nm}$ laser delivering $8 \mathrm{~mW}$ total power.
To test ICSS reinforcement by the $\mathrm{dMHb}$, mice were placed into an operant chamber (ENV-307W, Med Associates) with two response wheels that record one event for every 90 degrees of rotation (ENV113AMW, Med Associates). The wheel turning responses were recorded through baseline, stimulated, and reversal sessions as described below.

Baseline sessions. Spontaneous wheel turning behavior was recorded for three $45 \mathrm{~min}$ baseline sessions during which no laser stimulation was delivered. To counterbalance any initial side bias in wheel turning behavior, the wheel recording the larger number of turns in the baseline sessions was designated the "initially preferred side" $(\mathrm{P})$ and the wheel with fewer turns was designated "the initially nonpreferred side" (NP). For the initial sessions with delivery of a laser stimulus, the NP wheel was chosen as the "active" wheel associated with the laser simulation. Thus subjects must overcome any initial bias to develop a preference for the active wheel in stimulated sessions.

Stimulated sessions. After the baseline sessions, mice underwent three 45 min ICSS sessions in which the active (NP) wheel was associated with the delivery of laser stimulation via an implanted fiber optic cannula (above), and the $\mathrm{P}$ wheel was inactive. Each trial consisted of a variable response period during which wheel turning events on the active wheel were recorded until the reward criterion was met, followed by a $20 \mathrm{~Hz}$ train of $25 \mathrm{~ms}, 8 \mathrm{~mW}$ laser pulses for $4 \mathrm{~s}$, and a $2 \mathrm{~s}$ time out period. Wheel turning events during the period of laser stimulation and time out were recorded but did not count toward a reward. Wheel turning events on the inactive wheel were recorded; during the response period, responses on the inactive wheel reset the event counter to 0 . Within each session, the reward criteria were escalated such that the first five trials required one response, the next five trials required five responses (the "training trials"), and subsequent trials required 25 responses to trigger delivery of the laser pulse train. The low fixed ratio of response:reward in the training trials was designed such that all mice received some rewards as a result of spontaneous wheel turning.

Reversal sessions. The reinforcing effect of ICSS was then confirmed in reversal sessions during which the active wheel was switched to the P side. The trial and session structure in the reversal sessions was the same as the initial stimulation sessions. Mice received three or six 45 min crossover sessions; only the last three sessions were used for analysis. The same cohort of mice was used for all the ICSS experiments $\left(n=12 \mathrm{dMHb}{ }^{\text {ChR2 }}\right.$ and 10 control mice).

IP optogenetic inhibition studies. Optogenetic inhibition studies were performed with $\mathrm{dMHb} \mathrm{NpHR}^{\mathrm{NpH}}$ optogenetic mice and controls that lacked either the Ai39 or Cre driver allele. All tests were conducted using male mice between 6 and 8 months of age. Mice were implanted with a cannula consisting of a single $100 \mu \mathrm{m}, 0.22 \mathrm{NA}$ optical fiber (Thor Laboratories) that protruded $5 \mathrm{~mm}$ from the connecting ferrule and Delrin guide. The point of insertion at the skull was at bregma $-3.52 \mathrm{~mm}$ and lateral -1.57 $\mathrm{mm}$, at a -20 degree angle relative to the midline. The targeted coordinates for the cannula tip were as follows: rostrocaudal, bregma -3.52 $\mathrm{mm}$; dorsoventral, $-4.29 \mathrm{~mm}$ ventral to the lambda-bregma line; lateral, at midline. The implanted optical fibers were connected as described for the optogenetic activation experiments. The tracking of mouse body movements and event-triggered laser activation were controlled by EthoVision XT (Noldus Information Technology).

Optogenetic open field locomotion and acute place preference/aversion in $d M H b^{N p H R}$ mice. The open field sessions for $\mathrm{dMHb}$ output inhibition in control and $\mathrm{dMHb}{ }^{\mathrm{NpHR}}$ mice consisted of $5 \mathrm{~min}$ of habituation, $10 \mathrm{~min}$ of baseline activity, and $10 \mathrm{~min}$ of intermittent laser illumination, consisting of $30 \mathrm{~s}$ laser-on periods and $30 \mathrm{~s}$ laser-off periods $(640 \mathrm{~nm}, 8 \mathrm{~mW}$ from the end of the patch cord).

Optogenetic place preference/aversion studies were conducted in a three-chamber place-preference box (ENV-3013, Med Associates). The laser-active lateral chamber was distinguished by vertically striped walls and stainless steel grid rods for flooring, whereas the inactive lateral chamber had horizontally striped walls and metal mesh flooring. The small central entry chamber had a smooth floor. Recording and event triggering were controlled with EthoVision XT using center point tracking. Sessions were initiated by placing the mouse in the center compartment of the apparatus. The mice were then given free access to all three chambers for $15 \mathrm{~min}$. When the mouse entered the active chamber, the 
$640 \mathrm{~nm}$ laser was activated, delivering continuous illumination at $8 \mathrm{~mW}$ of total power from the end of the patch cord, which remained on until the mouse entered the inactive chamber. Conversely, after occupancy of the inactive chamber, the laser remained off until the mouse entered the active chamber. Thus, time spent in the central chamber was scored as active chamber time or inactive chamber time depending on the state of the laser linked to the immediately prior occupancy of a lateral chamber. Mean time spent in the center chamber was (give percentage), and inclusion or exclusion of the center time did not significantly affect the analysis. Active and inactive chamber occupancy and total distance traveled were then calculated for each 5 min interval of the 15 min session.

General statistical methods. Statistical analyses were conducted using unpaired or paired two-tailed $t$ tests, two-way ANOVA, or two-way repeated-measures ANOVA with Bonferroni's post hoc analyses in GraphPad Prism 6 (GraphdPad Software). Results are presented as mean \pm SEM.

\section{Results}

Conditional deletion of the transcription factor gene Pou 4 f 1 results in nearly complete loss of dMHb neurons

Mice that are homozygous for a constitutive Pou4f1 (Brn3a, Brn3.0) null allele die at birth, probably from the loss of brainstem cholinergic neurons in the nucleus ambiguus (McEvilly et al., 1996). To circumvent this neonatal lethality, and allow the habenula-specific excision of Poutf1, we generated a line of mice in which exon 2 of the Pou 4 f1 gene, containing nearly all of the coding sequence, is flanked by loxP sites (Fig. 1A). We then excised the neomycin selection cassette from transgenic founders to yield the allele Pou $4 f_{1} 1^{\text {flox }}$ (see Materials and Methods). Pou4fi $1^{\text {floxfflox }}$ mice are fertile, exhibit no obvious behavioral abnormalities, and express levels of Brn3a protein that are not distinguishable from wild-type by immunofluorescence. Mice lacking tissue-specific expression of Brn3a were generated by interbreeding mice bearing an appropriate Cre driver and a constitutive Pou $4 \mathrm{fl}$ null allele with mice bearing the genotype Pou $4 f^{\text {floxfflox }}$. The null allele used, Pou $41^{\text {tlac }}$, contains a lac $Z$ expression cassette replacing the Pouff1 coding sequence that allows the identification of neurons normally fated to express Brn3a in the absence of Brn3a protein (Quina et al., 2005). A database screen for potential Cre drivers for the $\mathrm{dMHb}$ revealed a synaptotagmin-6 BAC Cre line (Syt6 $\left.{ }^{\mathrm{Cre}}\right)$, generated by the Gensat project, as a candidate driver. Mice bearing this allele were recovered from a repository (see Materials and Methods), and its specificity was tested using a reporter line, Ai6, which conditionally expresses the fluorescent protein ZsGreen (Madisen et al., 2010). An examination of ZsGreen expression in the habenula of phenotypically normal mice showed that Cre activity in the MHb was confined almost entirely to the dorsal part, and activation of reporter expression in scattered neurons in the LHb was also noted (Fig. 1B,C). Although Syt6 ${ }^{\mathrm{Cre}}$ expression is not specific for the habenula, an examination of the sites of induced reporter expression throughout the CNS revealed very little coexpression of ZsGreen with Brn3a outside the habenula (Fig. $1 D-I)$. Conditional knock-out $\left(\mathrm{dMHb}^{\mathrm{CKO}}\right)$ mice used in the behavioral studies described below have the genotype Pou $4 \mathrm{f}^{\text {flox/tlacZ }}, \mathrm{Syt} \mathrm{C}^{\mathrm{Cre}}$, and control mice have the genotype Pou $41^{f l o x /+}$, Syt $6^{\text {Cre }}$. Because Syt $6^{\text {Cre }}$ and Brn3a coexpression is largely restricted to the habenula, any loss of function induced by this combinatorial strategy should be habenula-specific.

When we examined adult $\mathrm{dMHb}^{\mathrm{CKO}}$ mice for the expected loss of Brn3a protein using immunofluorescence, we immediately observed that the $\mathrm{dMHb}$ in these mice exhibited profound cell loss. Immunostaining for Brn3a and $\beta$-gal protein expressed from the Pou $4 \mathrm{ft}^{\text {tlac } Z}$ allele showed that the dMHb was markedly reduced in size, and also that the small number of surviving $\beta$-gal ${ }^{+} \mathrm{dMHb}$ neurons often lacked Brn3a protein (Fig. 2A,B). Because the extent of the $\mathrm{dMHb}$ is not markedly reduced in late embryonic mice (Quina et al., 2009), we conclude that Brn3a is required for the postnatal survival of $\mathrm{dMHb}$ neurons. Immunostaining for the vMHb-specific marker ChAT showed that the $\mathrm{vMHb}$ was of normal size in $\mathrm{dMHb}^{\mathrm{CKO}}$ mice (Fig. $2 C, D$ ). Quantitative analysis of the left/right cross-sectional area of the $\mathrm{dMHb}$ along its full rostrocaudal extent (bregma -1.0 to $-2.1 \mathrm{~mm}$ ), defined by cells expressing the $\beta$-gal marker but not ChAT, showed that the $\mathrm{dMHb}$ was reduced to $25.8 \%$ of its normal volume $\left(F_{(3,114)}=179.4, p<0.0001\right.$; Fig. $\left.2 E\right)$. Two-way ANOVA instead of repeated measures two-way ANOVA was used because of missing measurements in the dataset (occasional lost sections). Two-way repeated-measures ANOVA was conducted to examine the extent of the $\mathrm{dMHb}$ lesion in a large behavioral cohort of mice, which shows a consistent effect on cell loss $\left(F_{(1,21)}=552.7\right.$, $p<0.0001$; Fig. $2 F$ ).

We also used ISH to characterize the expression of mRNA for Tac1 (encoding SP) and the $\mathrm{K}^{+}$-channel interacting protein Kcnip1, which have been previously described as specifically expressed in the $\mathrm{dMHb}$ and $\mathrm{vMHb}$, respectively (Quina et al., 2009). The area of Tacl expression was markedly reduced, whereas the area of Kcnip1 expression appeared unchanged (Fig. $2 G-J)$.

\section{Ablation of $\mathrm{dMHb}$ neurons reduces voluntary wheel running and rotarod performance with relatively minor changes in other motor tests and normal locomotion}

To assess the role of $\mathrm{dMHb}$ in behavior, we began by measuring voluntary WRA in control and $\mathrm{dMHb}^{\mathrm{CKO}}$ mice. Most rodents will voluntarily engage in WRA, and in rats it has been shown to specifically act as a reinforcer for other behaviors, such as a lever press, leading to studies of the interaction of WRA with other reward systems (Sherwin, 1998; Novak et al., 2012). Nocturnal animals, such as mice, housed under conditions with an alternating LD condition, exhibit most of their WRA in the dark phase. Both control and $\mathrm{dMHb}^{\mathrm{CKO}}$ mice entrained to the 12:12 LD cycle and, as expected, exhibited more WRA during the dark period between zeitgeber time (ZT) 12 (time of lights off) and ZT0 (time of lights on; main effect of time, $F_{(23,529)}=86.68, p<0.0001$; Fig. $3 A$ ). However, the overall WRA of $\mathrm{dMHb}{ }^{\mathrm{CKO}}$ mice was greatly reduced compared with control mice $\left(F_{(1,23)}=17.19, p=\right.$ 0.0004). Post hoc analyses indicated that this effect was driven by reduced activity of the $\mathrm{dMHb} \mathrm{CKO}^{\mathrm{CK}}$ mice during the first half of the night between ZT12 and ZT17 (Fig. 3B).

The observed reduction in WRA of the $\mathrm{dMHb}{ }^{\mathrm{CKO}}$ mice could result from a motor deficit leading to decreased locomotor ability or from decreased motivation to run, possibly reflecting an interaction with reward mechanisms. For this reason, we assessed the $\mathrm{dMHb} \mathrm{C}^{\mathrm{CKO}}$ mice in a series of motor tests, some of which also involve a sustained motivational component. We first administered the rotarod test, in which mice are required to stay on top of a rotating drum to avoid a harmless but aversive fall. The rod accelerates throughout the test, and the time elapsed until a fall is the principal outcome. A short falling latency indicates a deficit in the animal's ability or drive to maintain an upright position on the device. Although frequently used as a test of motor function, the rotarod includes a motivational component (incentive to avoid falling from the device), and chronic stress, a model of depression, impairs rotarod performance (Mizoguchi et al., 2002). After one training day at fixed speed, mice were tested on the accelerating rotarod for $2 \mathrm{~d}$ of four trials each (see Materials and Methods). The $\mathrm{dMHb}^{\mathrm{CKO}}$ mice exhibited shorter latency to 
A

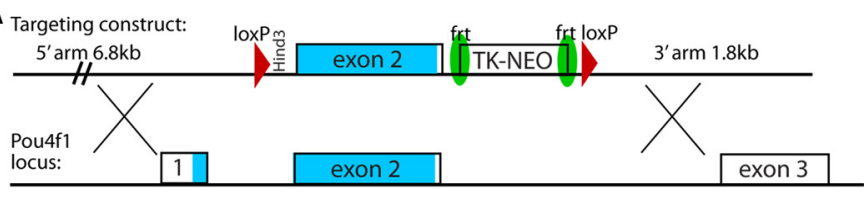

Targeted allele:

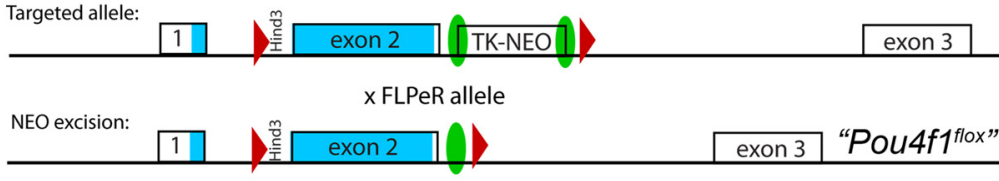

Conditional KO:

$x$ tissue-specific Cre allele

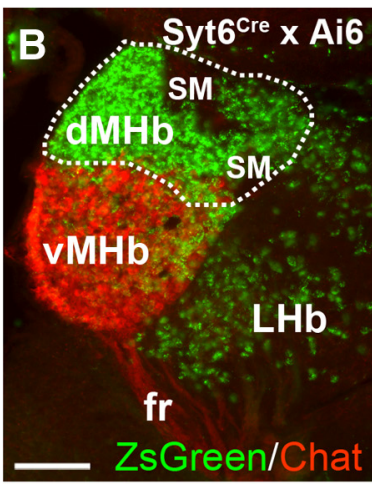

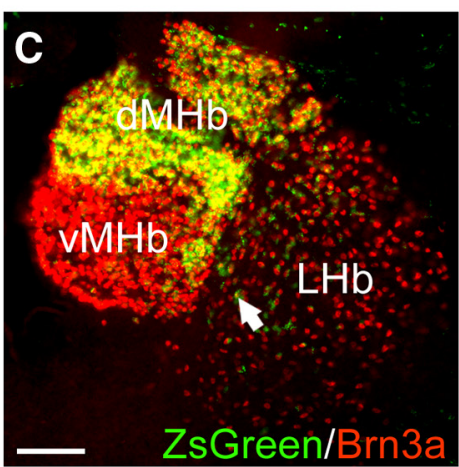
exon 3
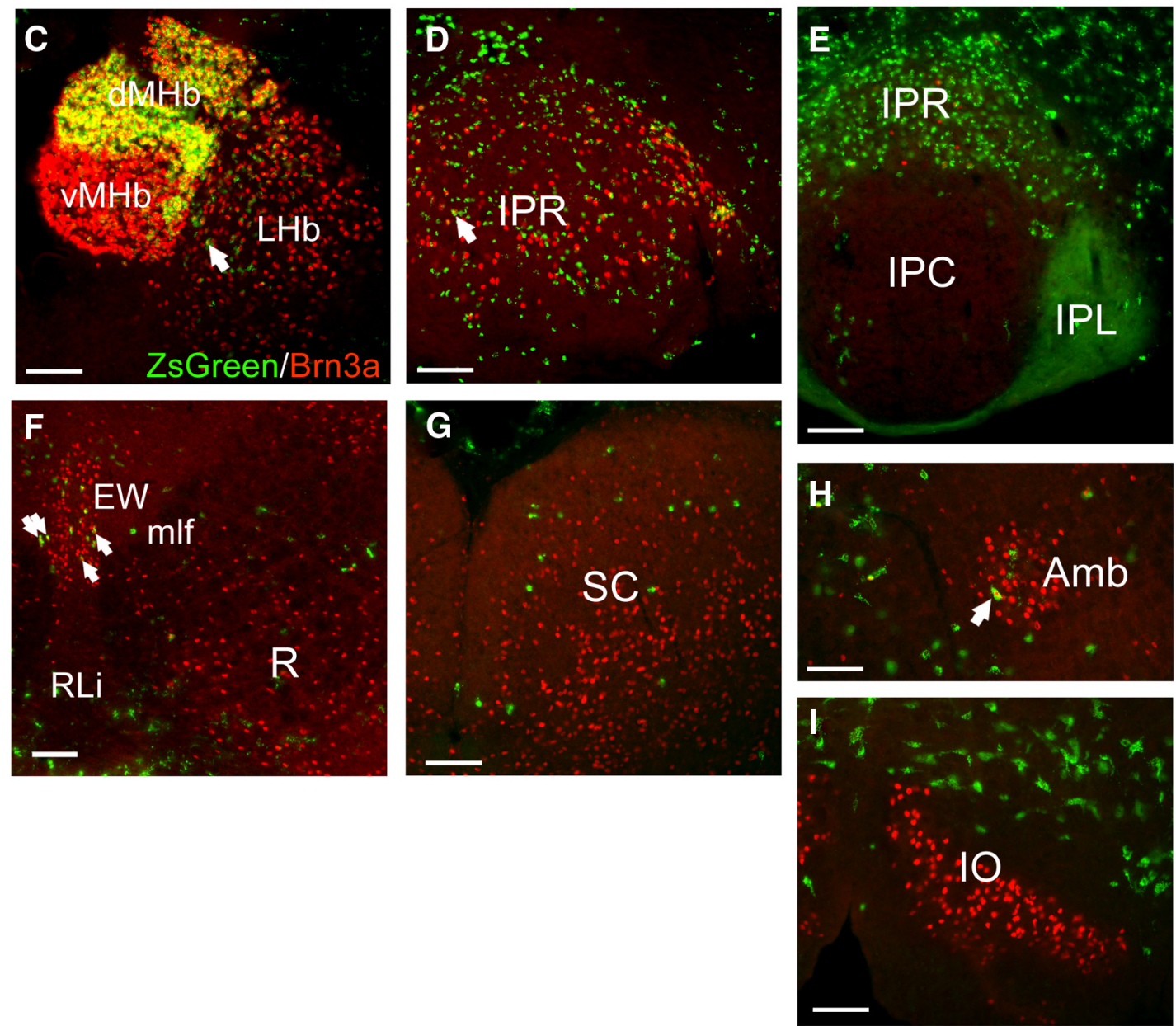

Figure 1. Structure of the Pou4ff $7^{\text {flox }}$ allele and expression of Brn3a and a Syt6 ${ }^{\text {Cre }}$-induced transgene in Brn3a-expressing brainstem nuclei. $\boldsymbol{A}$, Schematic of the Pou4f $1^{\text {flox }}$ allele structure. $\boldsymbol{B}$, Habenula expression of ZsGreen from Ai6, an inducible reporter line, driven by Syt $6^{\mathrm{Cre}}$. Syt ${ }^{\mathrm{Cre}}$ mice were interbred with mice bearing the Ai6 allele, which allows conditional expression of the fluorescent reporter ZsGreen from the Gt(Rosa) $26^{\text {Sor }}$ locus (Madisen et al., 2010). Neurons in the vMHb express acetylcholine and its synthesizing enzyme, ChAT, is used to distinguish this subnucleus from the dMHb. C-I, Syt6 Cre/Ai6 mice were examined for the expression of Brn3a protein and ZsGreen fluorescence in brain nuclei known to express Brn3a (Fedtsova and Turner, 1995). Brn3a immunofluorescence (red) is nuclear, whereas ZsGreen fluorescence is cytoplasmic, and also labels efferent fibers from areas of strong expression. Cellular colocalization thus produces a green periphery and yellow center. C, Syt $6{ }^{\mathrm{Cre}}$-induced ZsGreen is strongly coexpressed with Brn3a in the dMHb but not the vMHb. A subset of cells in the medial part of the LHb also express ZsGreen, and occasional coexpression with Brn3a is observed (example, arrow). D, Rostral IP. Numerous cells express ZsGreen and Brn3a, and sometimes overlap, but cellular colocalization is rarely observed. A rare example of possible colocalization is marked by the arrow. Note that the entire cell soma of most cells expressing ZsGreen is smaller than the nucleus of most cells expressing Brn3a. $\boldsymbol{E}$, Caudal IP. Few Brn3a-immunoreactive neurons are seen at this level. Zs Green labeling is seen in afferent IPL fibers from the dMHb. Specificity of this afferent projection for IPL (not IPC) confirms that Syt6 ${ }^{\text {re }}$ activated gene expression specific for the $\mathrm{dMHb}$, as defined by its principal target of innervation, IPL.F, Midbrain, ventral expression: colocalization of ZsGreen and Brn3a is observed in $<10 \%$ of the cells of the Edinger-Westphal nucleus; no colocalization is observed in the red nucleus. G, Midbrain, superior colliculus expression. No colocalization of Brn3a and ZsGreen is observed in this region. $\boldsymbol{H}$, Hindbrain. A single neuron with colocalized signal appears in the nucleus ambiguus (arrow). I, Hindbrain. No colocalization appears in the inferior olive. Amb, Nucleus ambiguus; EW, Edinger-Westphal nucleus; fr, fasciculus retroflexus; I0, inferior olive; IPC, interpeduncular nucleus, caudal; IPL, interpeduncular nucleus, lateral; IPR, interpeduncular nucleus, rostral; LHb, lateral habenula; mlf, medial longitudinal fasciculus; $\mathrm{R}$, red nucleus; RLi, rostral linear nucleus raphe; $\mathrm{SC}$, superior colliculus (of midbrain); $S M$, striae medularis; vMHb, medial habenula, ventral. 

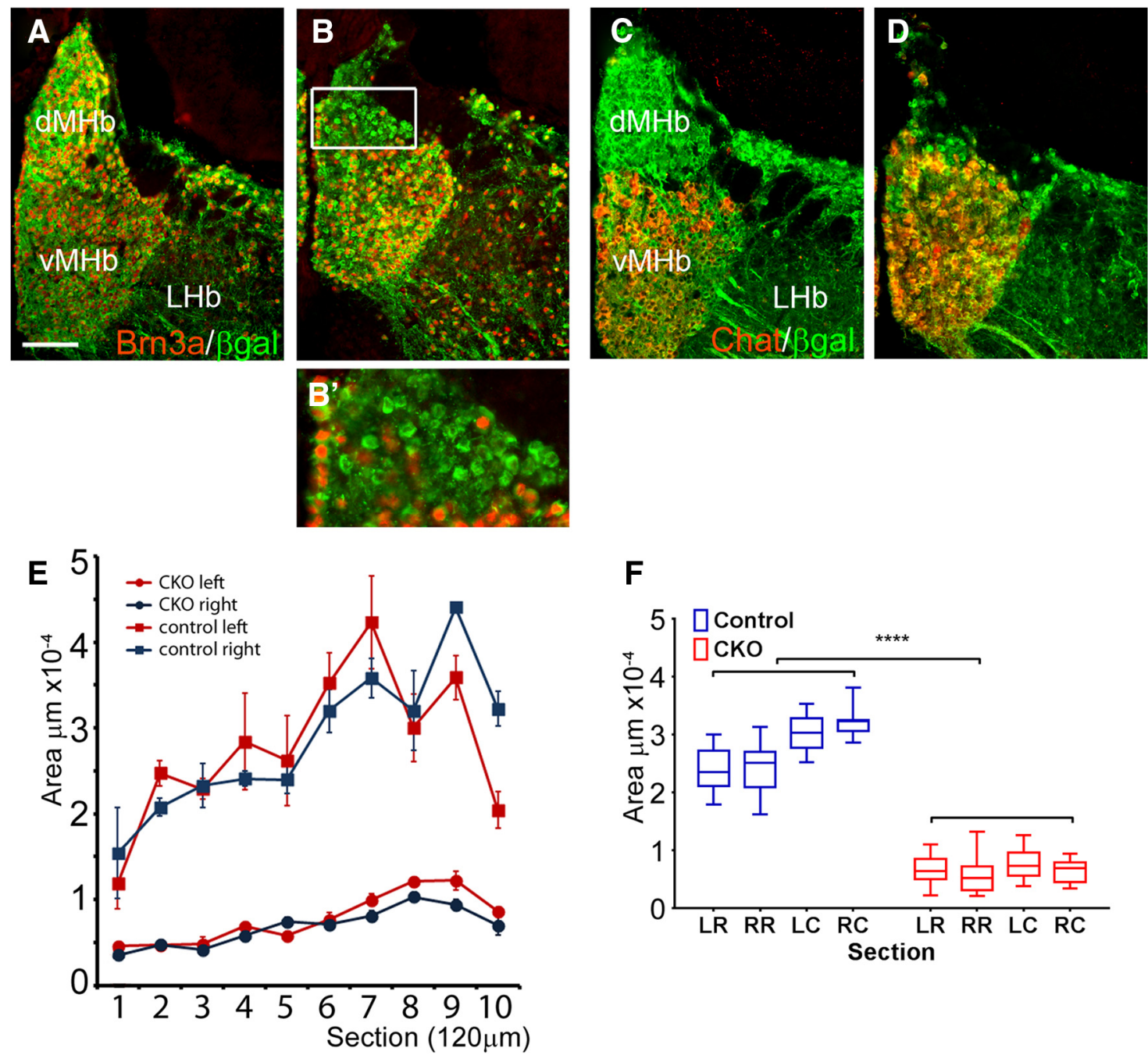

$\mathbf{F}$
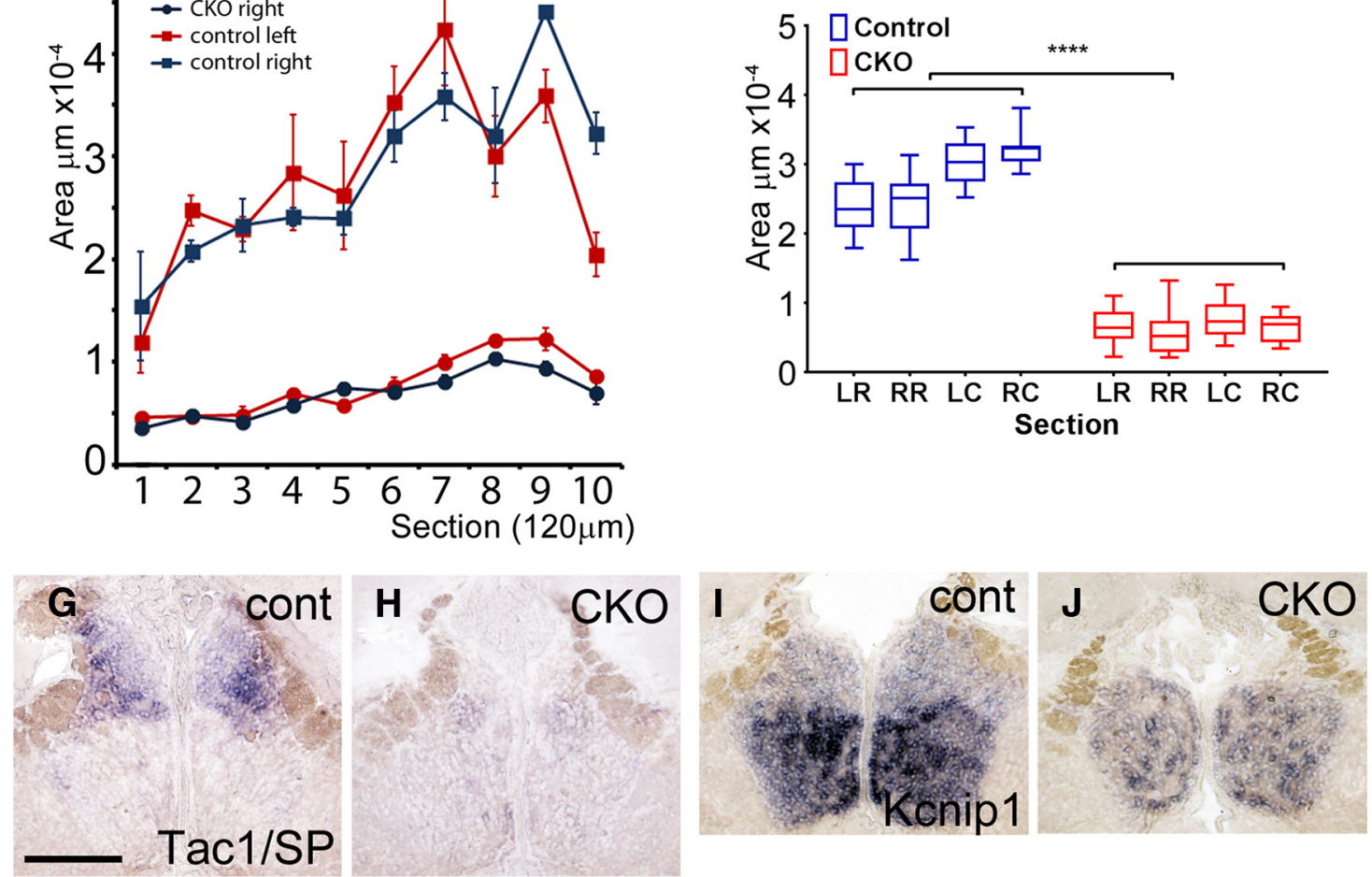

Figure 2. Characterization of the Syt $6^{\text {Cre }} /$ Pou $4 f f^{f l o x} \mathrm{dMHb}^{\mathrm{CKO}}$ mouse model. $A, B$, Brn3a nuclear immunostaining and a lacZ tracer targeted to the Pou $4 f 1$ locus are used to show the extent of the

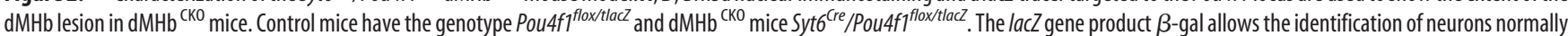
fated to express Brn3a in the absence of Brn3a protein. Nuclear Brn3a expression is reduced even in the surviving neurons in the dMHb of the dMHb ${ }^{\mathrm{CKO}}$ mice $\left(\boldsymbol{B}^{\prime}\right)$. No obvious change is observed in Brn3a expression in the $\mathrm{LHb}$, consistent with the infrequent colocalization of Syt6 ${ }^{\mathrm{Cre}}$ and Brn3a in this part of the habenula (Fig. 1C). C, D, Neurons of the vMHb, distinguished by ChAT expression, are intact in both the control $(\boldsymbol{C})$ and $\mathrm{dMHb}^{\mathrm{CKO}}$ mice $(\boldsymbol{D})$. $\boldsymbol{E}$, Comparison of the area of the $\mathrm{dMHb}$ in the coronal plane of section along the entire rostrocaudal extent of the $\mathrm{MHb}$ in control and dMHb ${ }^{\mathrm{CKO}}$ mice. Both the left and right dMHb is significantly reduced in the $\mathrm{MMHb}^{\mathrm{CK} 0}$ mice compared with control mice ( $n=3$ control and $n=7 \mathrm{dMHb}{ }^{\mathrm{CK} 0}$ mice). $\boldsymbol{F}$, Measurement of the area/extent of ablation in the entire behavioral cohort of control and $\mathrm{dMHb}^{\mathrm{CKO}}$ mice used in behavioral analyses. Sections were measured at two rostrocaudal levels: the rostral/central $\mathrm{MHb}$ at bregma $-1.6 \mathrm{~mm}$ and the caudal $\mathrm{MHb}$ at bregma $-1.9 \mathrm{~mm}$, corresponding to sections 6 and $9 \mathrm{in} E$. Immunostaining was used to define the dMHb and vMHb compartments as in $A-D$. LR, Left/rostral; RR, right/rostral; $L C$, left/caudal; $\mathrm{RC}$, right/caudal. The loss of dMHb neurons in $\mathrm{dMHb}{ }^{\mathrm{CK} O}$ mice was highly consistent and symmetrical ( $n=9$ control and $n=14 \mathrm{dMHb}{ }^{\mathrm{CK} 0}$ mice). G-J, (haracteristic expression patterns of habenula-enriched transcripts. SP/Tac1 and Kcnip1 transcripts are restricted to the $\mathrm{dMHb}$ and vMHb, respectively, in control mice. The area of the region expressing SP/Tac1 mRNA is greatly reduced, whereas the area of Kcnip1 expression is not affected in the $\mathrm{dMHb}^{\mathrm{CK} 0}$ mice. LHb, Lateral habenula.

fall compared with control mice across the four trials in the first testing session $\left(F_{(1,23)}=24.95, p<0.0001\right.$; Fig. $\left.4 A\right)$ and over the four trials combined on day $1\left(t_{(23)}=5.06, p<0.0001\right.$; Fig. $\left.4 B\right)$. In repeated testing, the performance on day 1 is predicative of that on day $2(r=0.66, p=0.0003$; Fig. $4 C)$. The latency increased across trials on day $1\left(F_{(3,69)}=5.34, p=0.0023\right)$, and post hoc analyses show a significant difference between the control and $\mathrm{dMHb}{ }^{\mathrm{CKO}}$ mice from trials $2-4(p<0.05)$, which suggests that the control mice also improved their performance as the trials progressed but the $\mathrm{dMHb}^{\mathrm{CKO}}$ mice did not. Although exposure to WRA has been shown to improve rotarod performance (Clark et al., 2008), the rotarod assessment preceded the WRA trials in 
A

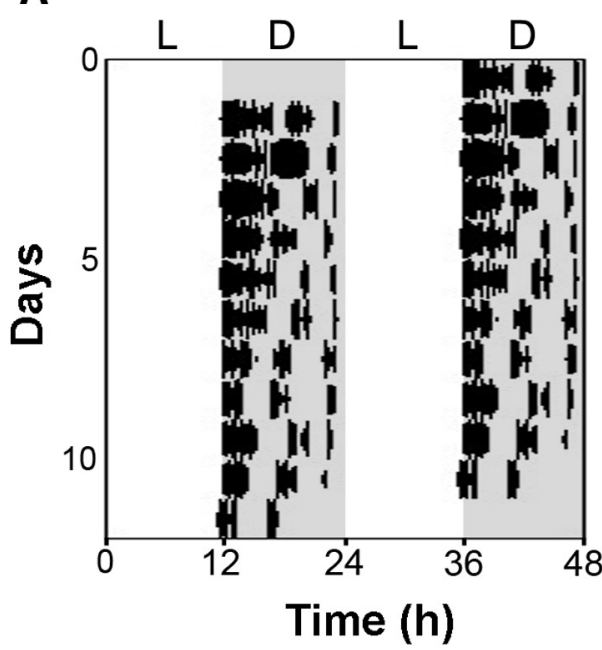

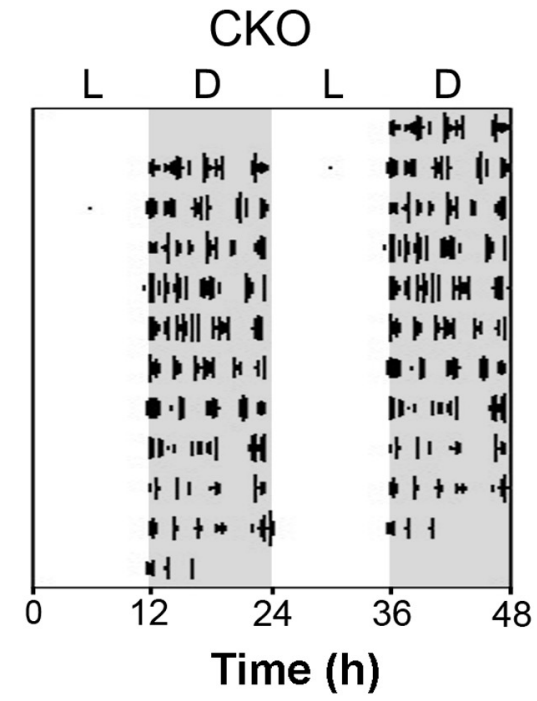

B

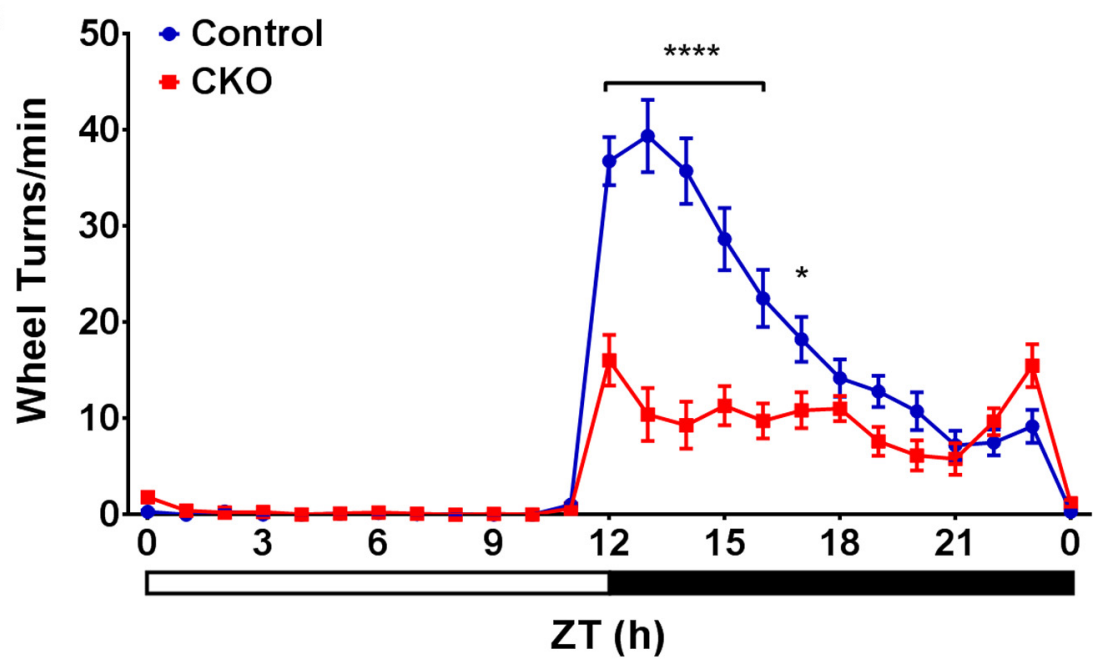

Figure 3. WRA of $\mathrm{dMHb}^{\mathrm{CK} 0}$ mice. Voluntary WRA was measured under a 12:12 LD cycle. $\boldsymbol{A}$, WRA in representative control and $\mathrm{dMHb}{ }^{\mathrm{CKO}}$ mice. WRA is displayed as double-plotted actograms with wheel turns as black bars on the vertical axis plotted against the $48 \mathrm{~h}$ period. White and gray areas represent time of lights-on and darkness, respectively. $\boldsymbol{B}$, Summary of WRA for control and $\mathrm{dMHb}{ }^{\mathrm{CKO}}$ mice over a $24 \mathrm{~h}$ day. $\mathrm{dMHb}{ }^{\mathrm{CKO}}$ mice showed significantly less WRA throughout the day, especially during the first of the night ( $n=11$ and $n=14$ for control and $\mathrm{dMHb}^{\mathrm{CKO}}$ mice, respectively). Eleven days of WRA were averaged for each of the control and $\mathrm{dMHb}^{\mathrm{CKO}}$ mice, with the exception for one control mouse where $7 \mathrm{~d}$ of averaged WRA was used. Zeitgeber time 12 (ZT12) corresponds to time of lights-off for a 12:12 LD cycle, and white and black bars below represent time of lights-on and darkness, respectively. Values for ZTO are replotted at the end for easier visualization. $N=11$ control and $N=14 \mathrm{dMHb}^{\mathrm{CKO}}$ mice. ${ }^{* * * *} p<$ 0.0001 (ZT12 to 16), significant difference between genotypes. ${ }^{*} p=0.024$ (ZT17), significant difference between genotypes.

12:12 LD cycle used in the housing area and were more active during the dark period (main effect of time, $F_{(23,529)}=13.03$, $p<0.0001)$. No difference was observed in distance traveled between control and $\mathrm{dMHb}^{\mathrm{CKO}}$ mice during the $24 \mathrm{~h}$ testing phase $\left(F_{(1,23)}=0.33, p=0.57\right.$; Fig. $\left.4 E\right)$.

To determine whether the WRA and rotarod performance results could be attributed to ataxia or other impairment of gait, we performed a detailed assessment using the CatWalk (Noldus Information Technology), which allows optical measurement of several gait parameters while the animal traverses a glass track (Table 1) (Gabriel et al., 2007). The dMHb ${ }^{\mathrm{CKO}}$ mice showed a nonsignificant trend toward shorter run duration compared with the control mice $\left(t_{(23)}=0.99, p=0.33\right)$. As expected, the shorter run time may be a result of faster limb swing speed and longer stride length for the $\mathrm{dMHb}^{\mathrm{CKO}}$ mice compared with controls. Limb swing speed normalized for run duration showed no difference between control and $\mathrm{dMHb}{ }^{\mathrm{CKO}}$ mice, nor did other measures of the form or regularity of gait (stands, duty cycle, and regularity index; Table 1). Small but significant differences were observed between control and $\mathrm{dMHb}{ }^{\mathrm{CKO}}$ mice in two other parameters, the forelimb "base of support" (BOS; Table 1), the measured distance between the front paws while walking, and the "print position," the distance between the imprint of a given hindpaw and the previous position of the ipsilateral front paw during the gait cycle (Table 1). The forelimb BOS was reduced for $\mathrm{dMHb}^{\mathrm{CKO}}$ mice compared with the control mice $\left(t_{(23)}=\right.$ $2.51, p=0.020)$, and the print position was closer (right paws, $t_{(23)}=2.69, p=$ 0.013 ; left paws, $t_{(23)}=2.58, p=0.017$ ). We note that, like the WRA and rotarod tests, the cohort of $\mathrm{dMHb}^{\mathrm{CKO}}$ mice showed a fairly broad distribution of individual performance values on these tests.

this cohort of mice, so the deficit in rotarod performance is not a secondary effect of the differential WRA of control and dMHb$\mathrm{CKO}$ mice.

We next assessed the $\mathrm{dMHb}^{\mathrm{CKO}}$ mice for spontaneous motor activity in an open field enclosure and in their home cages, and we performed a detailed assessment of their gait. In the open field test, $\mathrm{dMHb}{ }^{\mathrm{CKO}}$ mice traveled a similar distance compared with controls $\left(t_{(23)}=0.86, p=0.40 ;\right.$ Fig. $\left.4 D\right)$. In this test, the fractional time spent in the periphery versus the center of the enclosure is frequently used as a model of anxiety, and no significant difference was observed between control and $\mathrm{dMHb}{ }^{\mathrm{CKO}}$ mice in time spent in these areas $(p>0.05)$. To assess spontaneous locomotion in a more naturalistic environment, we usedPhenoTyper cages (Noldus Information Technology), which allow extended, undisturbed tracking of motor behavior in a home cage setting. As in the WRA experiments, both genotypes entrained to the
However, no significant correlation was observed between forelimbs BOS to WRA (control, $r=-0.057$; $\mathrm{dMHb}^{\mathrm{CKO}}, r=-0.11$ ) or rotarod performance (control, $r=-0.58$; $\mathrm{dMHb}^{\mathrm{CKO}}, r=$ -0.27 ). Similarly, no correlation was observed between print position (right paws) and WRA (control, $r=-0.15$; $\mathrm{dMHb}^{\mathrm{CKO}}$, $r=-0.12$ ) or latency to fall in the rotarod test (control, $r=0.22$; $\mathrm{dMHb}^{\mathrm{CKO}}, r=$ and -0.15$)$. Thus, the observed small differences in these gait parameters are unlikely to explain, or be related to, the reduced WRA or the impaired rotarod performance seen in the $\mathrm{dMHb}{ }^{\mathrm{CKO}}$ mice.

Subtle defects in motor function that may be missed in simple gait analysis may be detected by requiring mice to traverse a narrow balance beam (Brooks and Dunnett, 2009). The incentive to complete the task can be increased by requiring that mice cross a beam from an exposed platform to a platform enclosed by a "safe" box. To implement this test, we trained mice of both ge- 

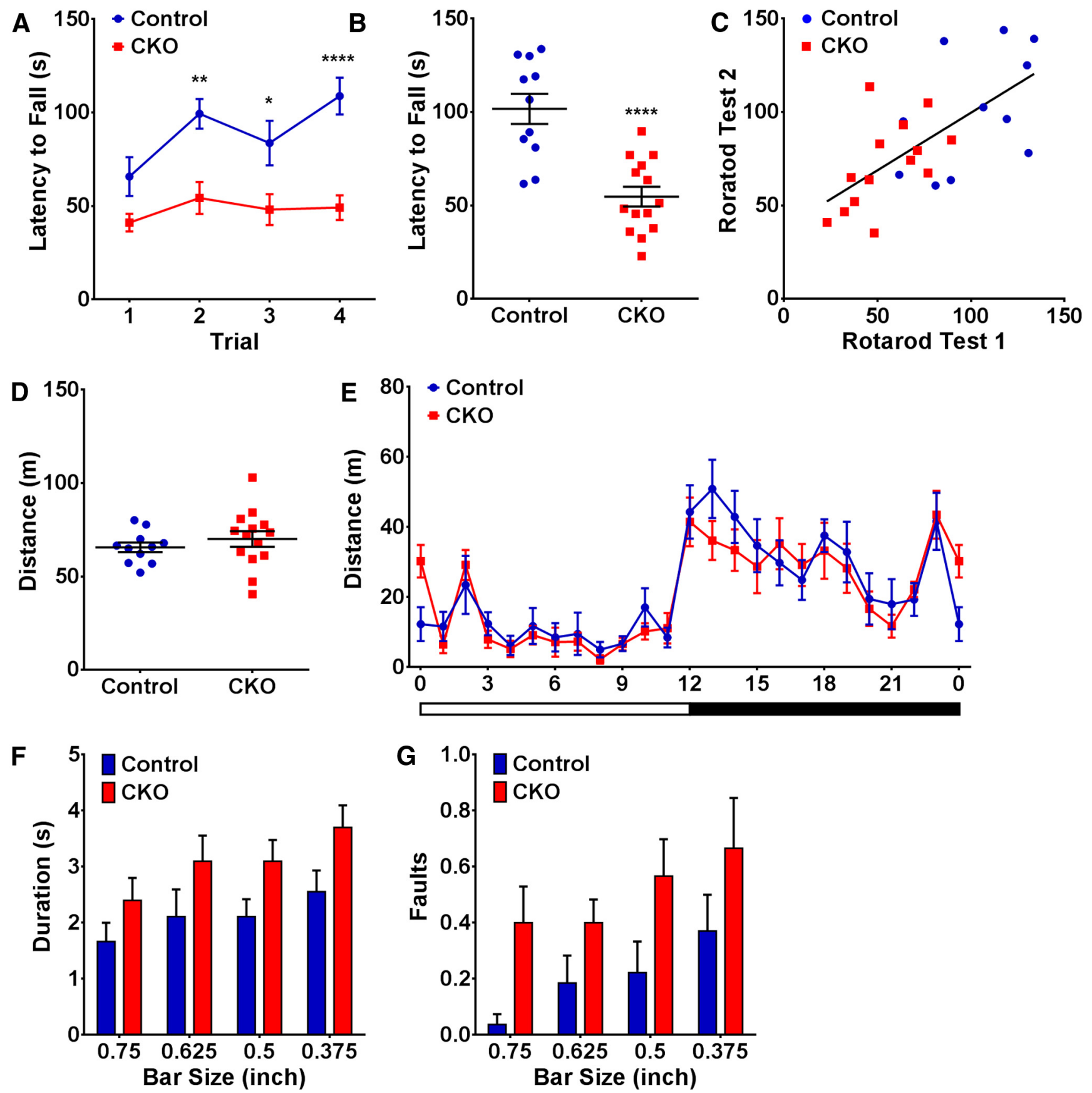

Figure 4. Rotarod performance, locomotion, and gait analysis in $\mathrm{dMHb}^{\mathrm{CK} 0}$ mice. $A$, Accelerating rotarod latency to fall times for dMHb ${ }^{\mathrm{CK} 0}$ mice over four trials on day 1 of testing compared with control mice, showing a significant relative deficit for $\mathrm{dMHb}^{\mathrm{CK} 0}$ mice in this test. ${ }^{*} p=0.02$, significant difference between genotypes for those trials. ${ }^{* *} p=0.0013$, significant difference between genotypes for those trials. ${ }^{* * *} p<0.0001$, significant difference between genotypes for those trials. $B$, Average latency to fall time in the rotarod for day 1 of testing (the lowest of the four values for each mouse was discarded before averaging). ${ }^{* * *} p<0.0001$. C, Correlation between latency to fall in the rotarod for four trials on day 1 versus day 2 of testing. Performance on day 1 is predicative of that on day $2 . r=0.66, p=0.0003$. D, Total distance traveled in the open field. No difference was observed for control and dMHb ${ }^{\mathrm{CK} 0}$ mice during the 30 min testing period. $\boldsymbol{E}$, Distance traveled in the home cage (PhenoTyper; Noldus Information Technology) tracked over a $24 \mathrm{~h}$ day, following $2 \mathrm{~d}$ of acclimatization. Both genotypes were more active during the night, as expected, and no differences were observed between genotypes. White and black bars below represent time of lights-on and darkness, respectively. The same cohort of mice was used for experiments in $\boldsymbol{A}-\boldsymbol{E}$ ( $n=11$ control and $n=14 \mathrm{dMHb}{ }^{\mathrm{CKO}}$ mice). $\boldsymbol{F}, \mathbf{G}$, Balance beam test. The test consisted of five trials on each of four successively smaller round beams, which were video recorded for analysis. The last three completed trials for each beam diameter were used to compute the average transit time $(\boldsymbol{F})$, and the average number of faults in which a rear paw lost contact with the beam $(\boldsymbol{G})$ for each subject. Overall, the $\mathrm{dMHb}^{\mathrm{CKO}}$ mice took longer to traverse the bars and committed more faults. $N=9$ control and $N=10 \mathrm{dMHb}{ }^{\mathrm{CKO}}$ mice.

notypes to perform the task on a 1 inch square beam, which did not present a physical challenge, then tested them with increasingly difficult round beams of $3 / 4,5 / 8,1 / 2$, and $3 / 8$ inch diameter. Trials were scored for the time of transit from the exposed platform to the safe box and for "faults" in which a hindpaw lost contact with the beam, resulting in a sudden shift in posture.
Although this test is in a sense voluntary, mice are highly motivated to escape to the safe location, and $100 \%$ of animals of both genotypes rapidly acquired the behavior. The abilities of control and $\mathrm{dMHb}{ }^{\mathrm{CKO}}$ mice to traverse the beam were grossly similar, as seen in side-by-side videos of mice of both genotypes that exhibited either zero or one fault in a representative trial (Movies 1 and 
Table 1. Overview of gait parameters measured in Noldus Catwalk

\begin{tabular}{|c|c|c|c|c|c|}
\hline Parameter & Definition & Paw & Control & CKO & $p$ \\
\hline Run duration (s) & Time for traveling down the walkway & & $2.93 \pm 0.23$ & $2.59 \pm 0.25$ & 0.33 \\
\hline \multirow[t]{4}{*}{ Swing speed $(\mathrm{cm} / \mathrm{s})$} & \multirow[t]{4}{*}{ Speed of movement } & RF & $45.65 \pm 1.76$ & $51.63 \pm 3.72$ & 0.20 \\
\hline & & $\mathrm{RH}$ & $56.84 \pm 1.48$ & $61.95 \pm 2.87$ & 0.16 \\
\hline & & $\mathrm{LF}$ & $45.46 \pm 1.88$ & $51.00 \pm 3.75$ & 0.24 \\
\hline & & $\mathrm{LH}$ & $58.96 \pm 1.86$ & $61.40 \pm 3.09$ & 0.53 \\
\hline \multirow[t]{4}{*}{ Normalized swing speed (cm) } & \multirow[t]{4}{*}{ Swing speed $\times$ run duration } & RF & $130.6 \pm 5.72$ & $122.4 \pm 3.76$ & 0.23 \\
\hline & & $\mathrm{RH}$ & $166.2 \pm 12.70$ & $152.0 \pm 8.21$ & 0.34 \\
\hline & & $\mathrm{LF}$ & $129.4 \pm 4.21$ & $120.7 \pm 4.10$ & 0.16 \\
\hline & & $\mathrm{LH}$ & $171.0 \pm 11.29$ & $150.3 \pm 8.20$ & 0.14 \\
\hline \multirow[t]{4}{*}{ Stride length ${ }^{b}(\mathrm{~cm})$} & \multirow[t]{4}{*}{ Distance between successive steps of the same paw } & $\mathrm{RF}$ & $5.50 \pm 0.29$ & $6.28 \pm 0.24$ & $0.048^{*}$ \\
\hline & & $\mathrm{RH}$ & $5.44 \pm 0.27$ & $5.96 \pm 0.201$ & 0.13 \\
\hline & & $\mathrm{LF}$ & $5.54 \pm 0.29$ & $6.22 \pm 0.21$ & 0.062 \\
\hline & & $\mathrm{LH}$ & $5.35 \pm 0.26$ & $5.89 \pm 0.27$ & 0.17 \\
\hline \multirow[t]{4}{*}{ Stand (s) } & \multirow[t]{4}{*}{ Time of paw contact with the walkway } & $\mathrm{RF}$ & $0.19 \pm 0.013$ & $0.18 \pm 0.014$ & 0.49 \\
\hline & & $\mathrm{RH}$ & $0.23 \pm 0.017$ & $0.22 \pm 0.022$ & 0.72 \\
\hline & & $\mathrm{LF}$ & $0.19 \pm 0.012$ & $0.18 \pm 0.014$ & 0.55 \\
\hline & & $\mathrm{LH}$ & $0.23 \pm 0.016$ & $0.21 \pm 0.020$ & 0.48 \\
\hline \multirow[t]{2}{*}{ Base of support ${ }^{c}(\mathrm{~cm})$} & \multirow[t]{2}{*}{ Width between either the front of hind paws } & Front & $1.32 \pm 0.042$ & $1.17 \pm 0.041$ & $0.020^{*}$ \\
\hline & & Hind & $2.63 \pm 0.064$ & $2.64 \pm 0.054$ & 0.91 \\
\hline \multirow[t]{2}{*}{ Print position $^{d}(\mathrm{~cm})$} & \multirow[t]{2}{*}{ Distance between hind paw to previous position of ipsilateral front paw } & $\mathrm{RF}-\mathrm{RH}$ & $0.92 \pm 0.12$ & $0.45 \pm 0.13$ & $0.013^{*}$ \\
\hline & & LF-LH & $0.94 \pm 0.12$ & $0.47 \pm 0.13$ & $0.017^{*}$ \\
\hline \multirow[t]{4}{*}{ Duty cycle $(\%)$} & \multirow[t]{4}{*}{ Stand as a percentage of step cycle } & RF & $57.60 \pm 1.00$ & $55.51 \pm 1.03$ & 0.17 \\
\hline & & $\mathrm{RH}$ & $67.27 \pm 1.68$ & $65.97 \pm 1.61$ & 0.58 \\
\hline & & LF & $57.70 \pm 1.05$ & $55.29 \pm 1.25$ & 0.17 \\
\hline & & $\mathrm{LH}$ & $68.96 \pm 1.56$ & $64.76 \pm 1.39$ & 0.056 \\
\hline Regularity index (\%) & Normal step sequence pattern relative to paw placements & & $93.86 \pm 1.45$ & $91.57 \pm 2.04$ & 0.39 \\
\hline
\end{tabular}

${ }^{a}$ The same cohort of mice $\mathrm{dMHb}^{\mathrm{CKO}}$ and matched control mice was used for all of the experiments shown ( $n=11$ control and $n=14 \mathrm{dMHb}{ }^{\mathrm{CK} 0}$ mice). RF, Right front paw; RH, right hind paw; LF, left front paw; $\mathrm{LH}$, left hind paw. ${ }^{b}$ The distance between successive steps of the right front paw was longer in the $\mathrm{dMHb}^{\mathrm{CKO}}$ mice compared with the control mice.

${ }^{\mathrm{C}}$ Forelimb BOS was shorter for the $\mathrm{dMHb}^{\mathrm{CKO}}$ mice compared with the control mice.

${ }^{d}$ Print position was shorter in the $\mathrm{dMHb}^{\mathrm{CK} 0}$ mice compared with the control mice.

${ }^{*} p<0.05$.

2). Despite this, the $\mathrm{dMHb}{ }^{\mathrm{CKO}}$ mice traversed the bars somewhat more slowly than controls at all diameters $\left(F_{(1,68)}=11.70, p=\right.$ 0.0011 ; Fig. $4 F)$. Both control and $\mathrm{dMHb}^{\mathrm{CKO}}$ mice exhibited an average of less than one fault per trial, but $\mathrm{dMHb}^{\mathrm{CKO}}$ mice committed significantly more faults than controls $\left(F_{(1,68)}=12.62\right.$, $p=0.0007$; Fig. $4 G$ ). Post hoc analyses did not show a difference between beam sizes for either behavioral analysis.

\section{Mice with $\mathrm{dMHb}$ lesions exhibit alterations in sucrose preference, a measure of hedonic state, but not in the FST}

As a model of hedonic state, we assessed the behavior of $\mathrm{dMHb}$ ${ }^{\mathrm{CKO}}$ mice in the sucrose preference test. In this two-bottle choice paradigm, mice normally prefer a sweetened source of drinking water, and loss of this preference is observed in models of stress and depression (Willner et al., 1996; Strekalova et al., 2004; Couch et al., 2013). dMHb ${ }^{\mathrm{CKO}}$ mice showed a significantly reduced preference toward the sucrose solution compared with control mice averaged over the $4 \mathrm{~d}$ testing period $\left(t_{(23)}=2.14\right.$, $p=0.043$; Fig. $5 A$ ). Individual $\mathrm{dMHb}{ }^{\mathrm{CKO}}$ mice exhibited sucrose preference ranging from normal ( $\sim 80 \%$ sucrose consumed) to sucrose aversion $(<50 \%$ sucrose consumed). To better understand this range of outcomes, we performed a complete replication of the test, which showed retention of individual preferences and a high test-retest correlation $(r=0.82, p<0.0001$; Fig. $5 B)$. Average total fluid consumption across the $4 \mathrm{~d}$ testing period $\left(F_{(1,23)}=0.04, p=0.85\right)$ and average body weight $\left(t_{(23)}=1.02\right.$, $p=0.32)$ at the conclusion of the test were not significantly different between genotypes. The sucrose preference test was performed before WRA assessment in this cohort of mice, excluding a secondary effect of WRA experience on sucrose preference.
Given the reduced WRA and evidence for an anhedonic state seen in the $\mathrm{dMHb}^{\mathrm{CKO}}$ mice, we also evaluated these mice using the FST, a model of stress response and depression (Duman, 2010). Initially, mice will swim vigorously if placed in a waterfilled cylinder, but if escape is not possible, they will eventually stop swimming and exhibit only the minimum movements necessary to keep their heads above the water. The time that the animals spend immobile is recorded as the principal outcome of the test. Both the control and $\mathrm{dMHb}^{\mathrm{CKO}}$ mice swam vigorously in the beginning of the test, but immobility increased as the test progressed $\left(F_{(14,196)}=6.72, p<0.0001 ;\right.$ Fig. $\left.5 C\right)$. Both genotypes exhibited a similar degree of immobility time during the $15 \mathrm{~min}$ of testing $\left(F_{(1,14)}=1.11, p=0.31\right)$. Collectively, our data indicate that the $\mathrm{dMHb}{ }^{\mathrm{CKO}}$ lesion has a marked effect on motor behaviors with a significant sustained motivational component, such as WRA and the rotarod test, and also affects hedonic state as measured by sucrose preference. In contrast, this lesion has much less impact on gait and balance beam performance, and no detectable effect on basal locomotion in an open field or home cage. The most straightforward explanation for the marked reduction in WRA in $\mathrm{dMHb}{ }^{\mathrm{CKO}}$ mice would be a role of the $\mathrm{dMHb}$ in mediating the motivational aspects of WRA, perhaps through a link to reward pathways. However, it is also possible that the subtle gait and balance beam deficits detected in these mice could represent a slight motor deficit that could alter the motivation to run indirectly, perhaps by increasing the difficulty (i.e., cost) of the task. To help resolve this question we turned to optogenetic models of $\mathrm{dMHb}$ activation and silencing to assess the role of the $\mathrm{dMHb}$ in primary reinforcement and aversion. These acute, reversible optogenetic models also help to overcome the intrinsic 
limitation that the $\mathrm{dMHb}{ }^{\mathrm{CKO}}$ mice have a permanent developmental lesion, which may be partially subject to compensatory mechanisms.

\section{Activation of the dMHb is \\ intrinsically reinforcing}

Because dMHb ablated mice have changes consistent with anhedonia, we wished to test whether this nucleus can mediate primary reinforcement. The habenula complex has been shown to support conventional ICSS (Sutherland and Nakajima, 1981), but this method cannot distinguish the habenula itself from fibers of passage, nor the specific role of the habenula subnuclei in mediating the response. Thus, we used an optogenetic strategy to test whether $\mathrm{dMHb}$ neurons can mediate reinforcement. Experimental mice expressing a channelrhodopsin 2-EYFP fusion protein (ChR2-EYFP) specifically in the $\mathrm{dMHb}$ were generated by interbreeding the Syt ${ }^{\mathrm{Cre}}$ driver line, also used to generate the $\mathrm{dMHb}^{\mathrm{CKO}}$ mice, with the transgenic strain Ai32 (Madisen et al., 2012), which conditionally expresses ChR2-EYFP from the Gt(Rosa)26Sor locus (Fig. 6A). As expected, expression of the induced ChR2-EYFP protein was restricted largely to the dorsal part of the $\mathrm{MHb}$, and terminal fibers were present in the IPL (Fig. 6B). In the behavioral studies described below, experimental mice expressing $\mathrm{ChR} 2\left(\mathrm{dMHb}^{\mathrm{ChR} 2}\right)$ have the genotype Ai32, Syt6 ${ }^{\mathrm{Cre}}$, whereas control mice have the genotype Ai32.

To test the effectiveness of photostimulation of $\mathrm{dMHb}$ neurons in $\mathrm{dMHb} \mathrm{bh}^{\mathrm{Ch} 2}$ mice, we performed loose-seal cell-attached recording from $\mathrm{dMHb}$ cell bodies in acute slice preparations. Neurons in the $\mathrm{dMHb}$ exhibited slow, irregular spontaneous firing at baseline, consistent with prior reports of spontaneous habenula activity (Kim and Chang, 2005). Trains of blue light pulses elicited 1:1 spiking of action potentials from $\mathrm{dMHb}$ neurons at frequencies of up to $20 \mathrm{~Hz}$ (Fig. 6C). To perform bilateral light stimulation of the $\mathrm{dMHb}$, we constructed bilateral fiber optic cannulas for permanent implantation ( $100 \mu \mathrm{m}$ diameter, $2.4 \mathrm{~mm}$ long, spaced at $0.7 \mathrm{~mm}$; Fig. $6 D$; Materials and Methods). Using stereotaxic surgery (see Materials and Methods), the cannula tips were placed above the dorsal margin of the $\mathrm{dMHb}$, at a point approximately two-thirds of the way from the rostral to the caudal pole of the nucleus (near bregma $-1.6 \mathrm{~mm}$ ). Groups of control and $\mathrm{dMHb}^{\mathrm{ChR} 2}$ mice were cannulated in the same position, which was verified postmortem after the completion of behavioral testing (Fig. 6E).

To determine the effects of $\mathrm{dMHb}$ stimulation in vivo, we first used open field locomotion to assess the effects of dMHb activation on motor activity. In the open field test with intermittent laser stimulation, there was a significant interaction between genotype and laser on/off state $\left(F_{(1,16)}=8.13, p=0.012\right)$. The control mice showed no difference in distance traveled during the laser on and laser off periods (Fig. $6 F, H$ ), whereas the
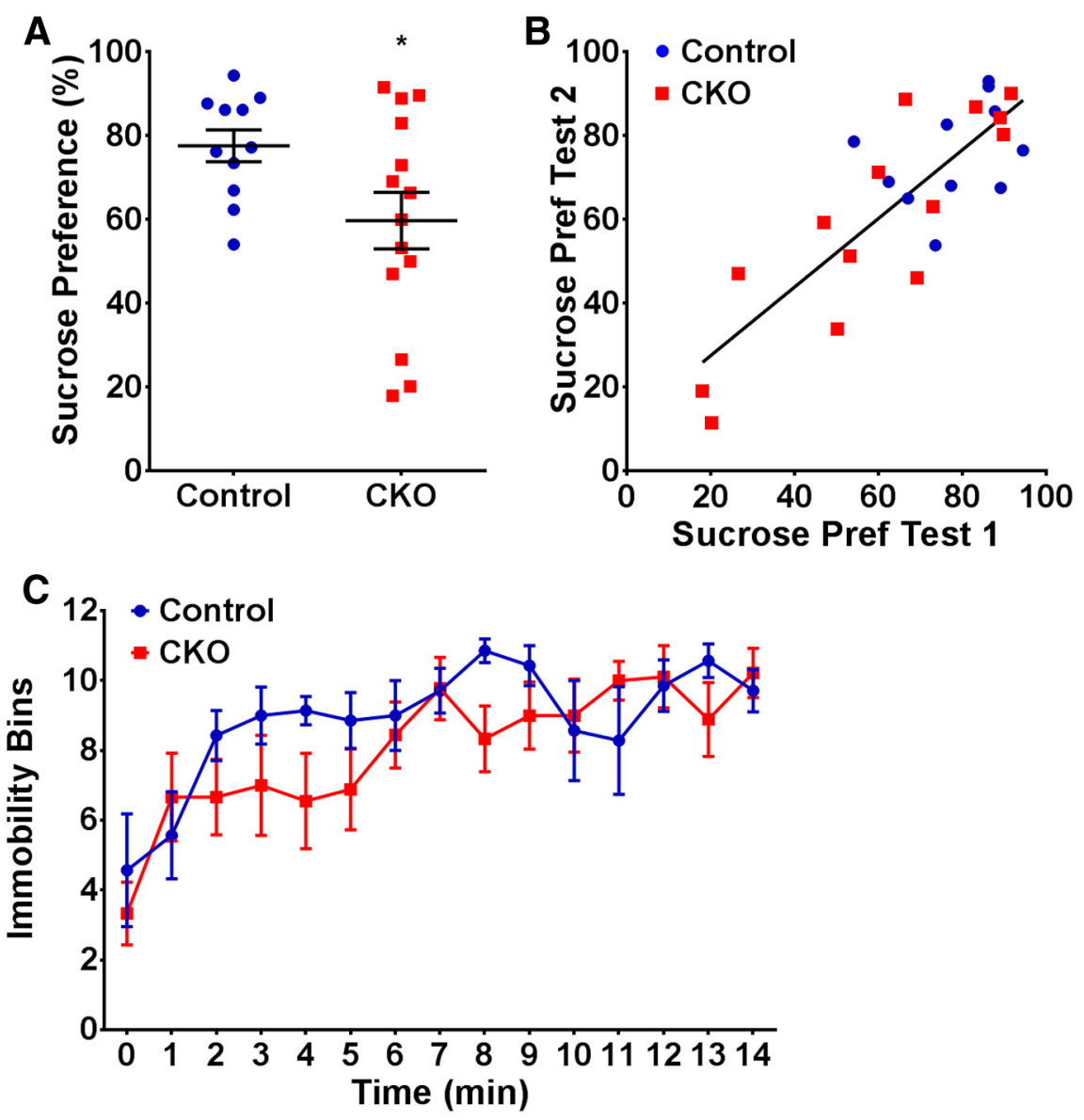

Figure 5. $\mathrm{dMHb}^{\mathrm{CK} 0}$ mice in models of hedonic state and depression. $\boldsymbol{A}$, Results for the sucrose preference test for each mouse correlation $(r=0.82, p<0.0001) . N=11$ control and $N=14 \mathrm{dMHb}^{\mathrm{CK} 0}$ mice. C, FST results for dMHb ${ }^{\mathrm{CK} 0}$ and control mice. Both genotypes were immobile for a similar amount of time during the 15 min test. $N=7$ control and $N=9 \mathrm{dMHb}^{\mathrm{CKO}}$ mice.

$\mathrm{dMHb}{ }^{\mathrm{ChR} 2}$ mice showed greater distance traveled during the laser on periods, especially during the initial intervals of light stimulation (Fig. 6G,H). Post hoc analyses indicated a significant overall effect of light stimulation on locomotion in $\mathrm{dMHb} \mathrm{ChR}^{\mathrm{Ch}}$ mice $(p=0.0051)$, whereas control mice did not exhibit a significant change in locomotion with light (Fig. $6 H$ ).

To investigate the specific role of the $\mathrm{dMHb}$ in primary reinforcement, we implemented an ICSS paradigm using an operant chamber with two response wheels (Fig. 7A,B). ICSS sessions were conducted daily for $9 \mathrm{~d}$. Three baseline sessions were obtained without laser stimulation, during which the mice exhibited low levels of spontaneous wheel turning. The wheel eliciting the larger number of turns in the baseline sessions was designated the initially preferred side $(\mathrm{P})$ and the other wheel the initially nonpreferred side (NP). To counterbalance any preexisting bias, the laser stimulation was initially linked to turns on the NP wheel. Three testing sessions were then performed with light pulses delivered for responses on the NP wheel (sessions 4-6), followed by three crossover sessions with stimulation delivered for responses on the P wheel (sessions 7-9).

Examples of individual responses for one $\mathrm{dMHb}{ }^{\mathrm{ChR} 2}$ mouse and one control mouse are shown in Figure $7 C$ and Figure $7 D$, respectively. Occasional wheel turning was observed during the baseline sessions in both genotypes (Fig. 7C,D, sessions 1-3). In 
A
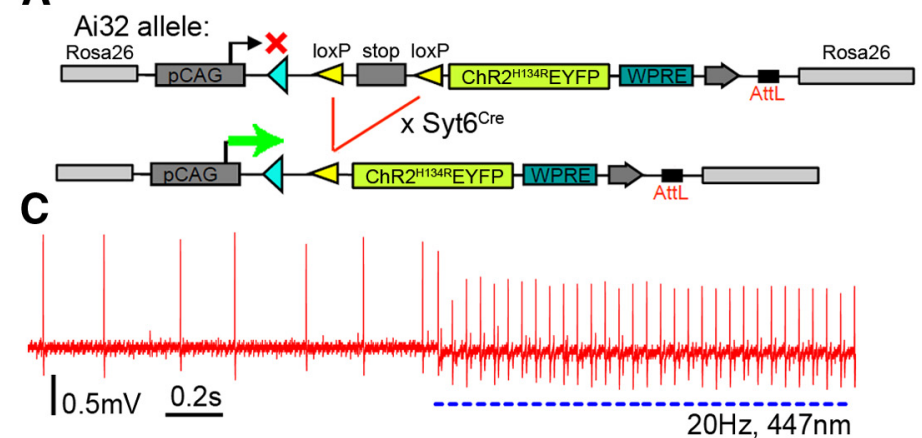

D $\quad 1 / 1 / 1$
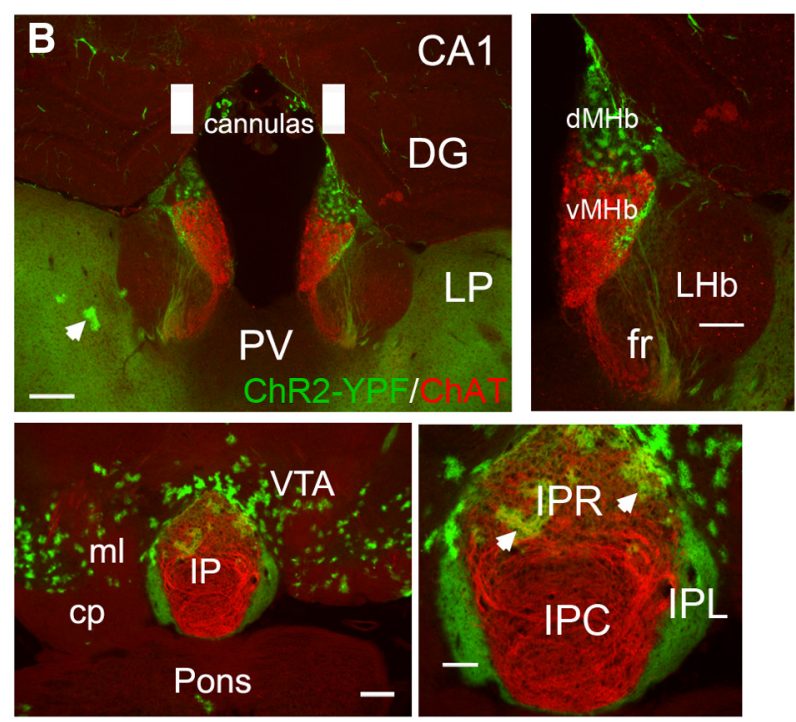

E
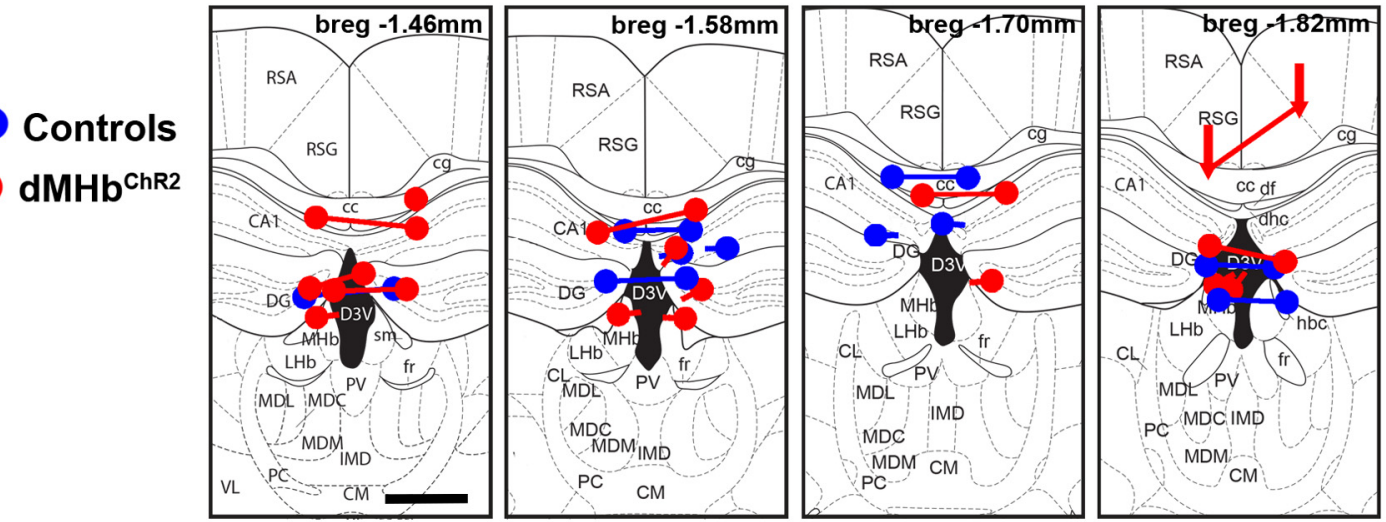

F

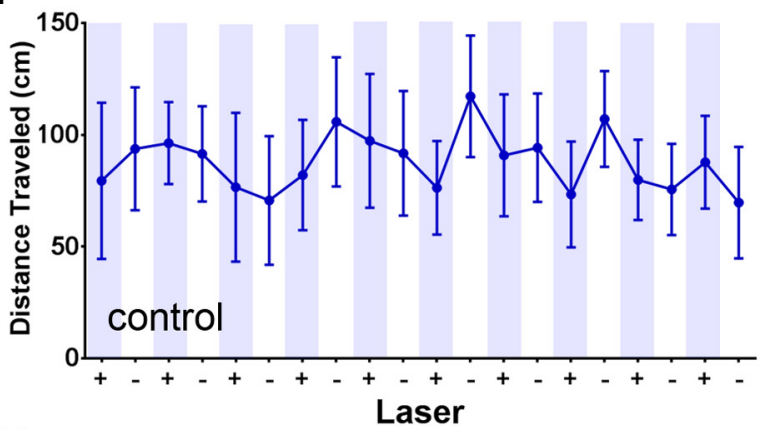

H

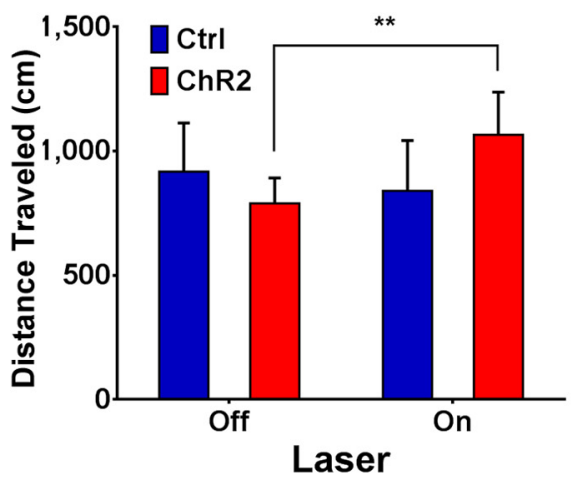

G

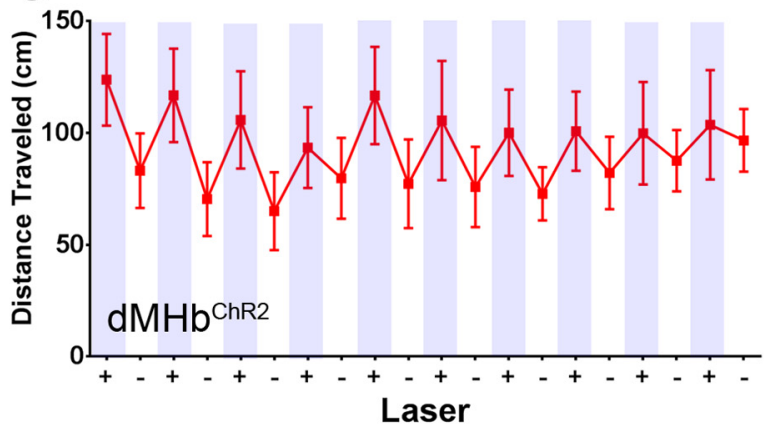

Figure 6. An optogenetic model for dMHb function and the effect of dMHb stimulation on locomotion. $\boldsymbol{A}$, Transgenic strategy for conditional expression of ChR2-EYFP in the dMHb. $\boldsymbol{B}$, Syt $6{ }^{\text {Cre }}$-driven expression of ChR2-EYFP from the Ai32 reporter in the dMHb (top) and IPL (bottom). EYFP expression is also seen in some scattered cells, which have the appearance of astrocytes (arrows). EYFP-labeled terminal fibers are also observed in the lateral posterior thalamic nucleus (LP); these are projections from layer 5/6 cortical neurons. (Figure legend continues.) 
sessions with stimulation linked to the NP wheel (sessions 4-6), the $\mathrm{dMHb} \mathrm{Ch}^{\mathrm{Ch} 2}$ mouse showed a marked increase in wheel turning and a strong preference for the stimulated wheel by session 5 . When the stimulation was switched to the P wheel (sessions 7-9), a high response rate on the NP wheel persisted for one session (session 7) but soon extinguished, and the turning behavior switched to the $\mathrm{P}$ wheel thereafter. In contrast, the control mouse did not exhibit increased wheel turning or preference (Fig. 7D, sessions 4-9).

We also examined total wheel turns, total stimulations delivered, and the establishment of side preference for the entire control and $\mathrm{dMHb} \mathrm{b}^{\mathrm{ChR} 2}$ groups. The effect of the laser stimulation was different between control and $\mathrm{dMHb}{ }^{\mathrm{ChR} 2}$ mice, indicated by the significant interaction between genotype and day $\left(F_{(8,160)}=\right.$ 4.52, $p<0.0001)$. The $\mathrm{dMHb}{ }^{\mathrm{ChR2}}$ mice exhibited more wheel turnings compared with the control mice $\left(F_{(1,20)}=5.31, p=\right.$ $0.032)$, and wheel turnings increased over sessions $\left(F_{(8,160)}=\right.$ $6.34, p<0.0001)$. Post hoc analyses indicate a trend for increased wheel turns exhibited by $\mathrm{dMHb}{ }^{\mathrm{ChR} 2}$ mice in the first two stimulated sessions, which reached significance by the third stimulated session (Fig. 7E, session 6; $p=0.013$ ). As expected, the frequency of laser activation ("rewards") received followed a similar pattern of differential responding by genotype $\left(F_{(8,160)}=4.54, p<\right.$ 0.0001 ; Fig. $7 F)$. The $\mathrm{dMHb}^{\mathrm{ChR} 2}$ mice received significantly more rewards compared with the control mice $\left(F_{(1,20)}=9.35, p=\right.$

\section{$\leftarrow$}

(Figure legend continued.) No EYFP-labeled fibers or cell bodies are observed in the paraventricular thalamus immediately ventral to the IP. No labeled fibers are observed in the VTA or other tegmental areas adjacent to the IP. White rectangles represent the targeted position and size of the implanted fiber optic cannula. Scale bar: low-power views, $200 \mu \mathrm{m}$; high-power views, $100 \mu \mathrm{m}$. C, Loose-seal cell-attached recording showing light-induced action potentials in the $\mathrm{dMHb}$ in a $\mathrm{dMHb}^{\mathrm{ChR2}}$ mouse. Irregular spontaneous firing at $\sim 3 \mathrm{~Hz}$ is observed at baseline. Application of $447 \mathrm{~nm}$ blue light pulses $\left(20 \mathrm{~ms}, 2.0 \mathrm{~mW} / \mathrm{mm}^{2}\right)$ at $20 \mathrm{~Hz}$ elicits action potentials entrained to the pulse frequency. The maximum stimulation rate for which the cell shown would generate 1:1 action potentials was $\sim 20 \mathrm{~Hz}$; at higher stimulation frequencies, some light pulses failed to elicit spikes. At the end of a 10 s interval of pulsed light delivery, a period of suppressed firing was observed ( $\sim 7 s$, data not shown), followed by a gradual resumption of firing at the baseline rate. $\boldsymbol{D}$, Bilateral optical cannula for implantation in the $\mathrm{dMHb}$. Cannula consists of a zirconia ferrule (1) and a $0.1 \mathrm{~mm}$ polyimide-coated optical fiber $(2,5)$, a polyether ether ketone (PEEK) insert (3), and an acetal (Delrin) guide (4). The bracketed area is covered with a stainless steel protective sleeve before implantation. $\boldsymbol{E}$, Optical fiber placement in the habenula for in vivo optogenetic-stimulated control and $\mathrm{dMHb}^{\mathrm{ChR2}}$ mice. Blue represents fiber placement in control mice; red represents placement in $\mathrm{dMHb}^{\mathrm{ChR2}}$ mice. Fiber termini are shown on the level of a standard anatomical map (Paxinos and Franklin, 2001) closest to their rostrocaudal position at bregma $-1.46,1.58,1.70$, or $1.82 \mathrm{~mm}$. Nearly all of the cannulas thus were positioned within $\pm 0.2 \mathrm{~mm}$ of the intended coordinates at bregma $-1.6 \mathrm{~mm}$. Connected dots indicate the probable ventral termini of the optical fibers from each case. In some cases, the right and left optical fibers mapped most accurately to different planes of section and are shown by disconnected dots. If the cannula track could not be followed for the entire length of the optical fiber, the most ventral position and the direction of the cannula track observed are indicated by an arrow. In all cases, the optical fibers were intact and transmitted light efficiently when examined postmortem after the experimental protocol. Scale bar, $0.5 \mathrm{~mm}$. F, G, Distance traveled by control and $\mathrm{dMHb}^{\mathrm{ChR2}}$ mice during a 10 min open field trial with intermittent laser stimulation. + (shaded), 30 slaser-on periods; - 30 s laser-off periods. Mice were exposed to the open field and to laser stimulation before testing began to minimize effects of novelty. $\boldsymbol{H}$, Summary of open field locomotor data. The distance traveled is summed across all laser-on and laser-off epochs for each mouse. In a within-subjects comparison, the $\mathrm{dMHb}^{\mathrm{ChR2}}$ mice show significantly greater distance traveled during the laser-on than the laser-off periods, whereas control mice exhibit no difference. ${ }^{* *} p<0.01$, significant difference between laser on/off periods for $\mathrm{dMHb}^{\text {ChR2 }}$ mice. $N=7$ control and $N=11 \mathrm{dMHb}^{\text {ChR2 }}$ mice. cp, cerebral peduncle, basal part; DG, Dentate gyrus; fr, fasciculus retroflexus; IPC, interpeduncular nucleus, caudal; IPL, interpeduncular nucleus, lateral; IPR, interpeduncular nucleus, rostral; LHb, lateral habenula; LP, lateral posterior nucleus of thalamus; $\mathrm{ml}$, medial lemniscus; PV, paraventricular nucleus of thalamus; VTA, ventral tegmental area.
$0.0062)$, and the rewards received increased as the sessions progressed $\left(F_{(8,160)}=29.29, p<0.0001\right)$. Post hoc analyses indicate a trend for increased rewards received by $\mathrm{dMHb}{ }^{\mathrm{ChR} 2}$ mice in the first two stimulated sessions, which reached significance by the third stimulated session (Fig. $7 F$, session $6 ; p=0.0016$ ). Withinsubjects analysis for wheel preference for the $\mathrm{dMHb}^{\mathrm{ChR} 2}$ mice was analyzed by combining total wheel turns for the stimulated wheels (NP during 4-6 and P during 7-9) or the nonstimulated wheels (P during 4-6 and NP during 7-9) (Fig. 7G). There was a significant interaction between wheels and sessions $\left(F_{(5,110)}=\right.$ 3.94, $p=0.0025)$. The $\mathrm{dMHb}^{\mathrm{ChR} 2}$ mice showed increased wheel turns on the stimulated wheel $\left(F_{(1,22)}=8.37, p=0.0085\right)$ that increased over sessions $\left(F_{(5,110)}=2.98, p=0.015\right)$. Post hoc analyses indicate a trend toward increased wheel turning in the first two sessions (Fig. 7G, sessions 4 and 5), which reached significance by session 6 ( $p=0.0094)$. On the initial crossover session (7), wheel preference was mixed as responses to the previously stimulated wheel persisted, but strong preference for the new stimulated wheel was established by session $8(p=0.013)$. Within-subjects analysis for the control mice showed no difference between stimulated versus nonstimulated wheels $(p>0.05$, data not shown). Fractional wheel preference expressed as the ratio of NP turns/total turns showed a similar pattern. The $\mathrm{dMHb}^{\mathrm{ChR} 2}$ mice showed a differential relative preference for the NP wheel depending on whether or not it was the stimulated wheel $\left(F_{(8,160)}=5.03, p<0.0001\right)$. This relative preference for either the stimulated NP wheel ( $>50 \%$ on $y$-axis) or the stimulated $\mathrm{P}$ wheel $(<50 \%$ on $y$-axis $)$ persisted across the sessions $\left(F_{(8,160)}=\right.$ $12.69, p<0.0001$; Fig. $7 H)$. Overall, there was no difference of relative preference between the control and $\mathrm{dMHb}{ }^{\mathrm{ChR} 2}$ mice $\left(F_{(1,20)}=\right.$ $0.72, p=0.41)$, but post hoc analyses revealed a preference for the stimulated wheel by the $\mathrm{dMHb}{ }^{\mathrm{ChR} 2}$ mice that reached significance by the last NP-stimulated session ( $\operatorname{session} 6, p=0.022$ ) and the last crossover session (session $9, p=0.0071$ ).

Unlike the mean wheel turn counts for each group, the fractional wheel preference is not skewed by the performances of mice that gave especially large numbers of responses. The establishment and reversal of wheel preference also cannot be explained by a nonspecific increase in motor activity in the $\mathrm{dMHb}^{\mathrm{ChR} 2}$ mice. Together, these results demonstrate that the $\mathrm{dMHb}$ mediates primary reinforcement.

\section{Inhibition of tonic dMHb output to the IPL is aversive}

$\mathrm{MHb}$ neurons exhibit irregular spontaneous firing (Kim and Chang, 2005) and thus provide continuous excitatory input to the IP. If the $\mathrm{dMHb}$ mediates primary reinforcement, inhibition of this tonic input would be predicted to be aversive. The twowheel choice paradigm used to assess $\mathrm{dMHb}$ reinforcement is not suitable for assessing aversive responses because the wheel turning response cannot be inhibited below the low baseline rate of this behavior. Instead, we adopted an acute place preference/ aversion paradigm, which has been previously used to demonstrate aversive responses to the ChR2-mediated stimulation of the lateral habenula outputs to the tegmentum (Stamatakis and Stuber, 2012a).

Experimental mice expressing the light-activated inhibitory chloride pump/fluorescent reporter eNpHR3.0-EYFP specifi-

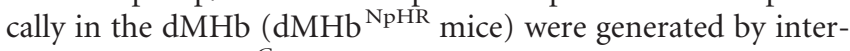
breeding the $S y t 6^{\text {Cre }}$ driver line (also used to generate the $\mathrm{dMHb}^{\mathrm{CKO}}$ and $\mathrm{dMHb} \mathrm{Ch}^{\mathrm{Ch} 2}$ mice) with the transgenic strain Ai39 (Madisen et al., 2012), which conditionally expresses eNpHR3.0EYFP from the Gt(Rosa)26Sor locus. Control mice were derived from the same crosses but lacked either the opsin or Cre driver 


\section{A Trial structure}

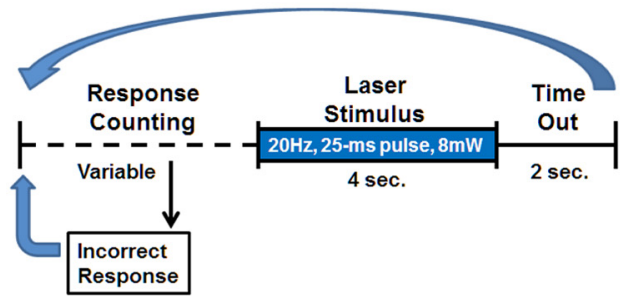

B Session structure:

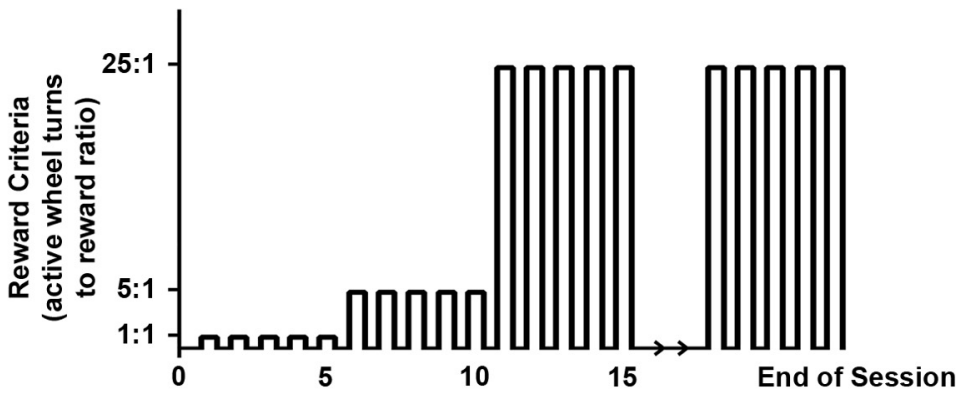

Trial number
C

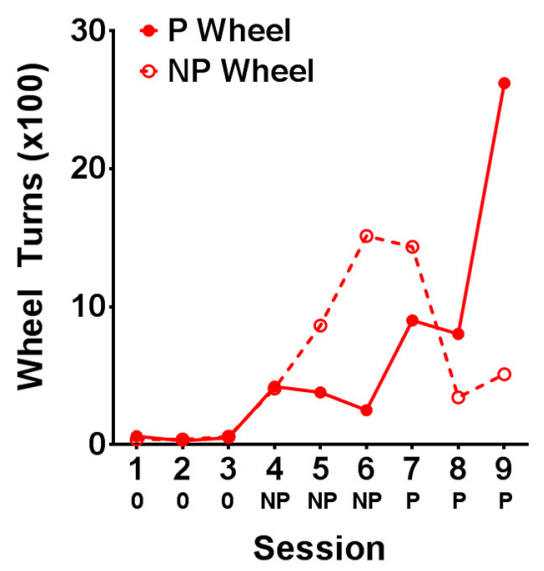

F

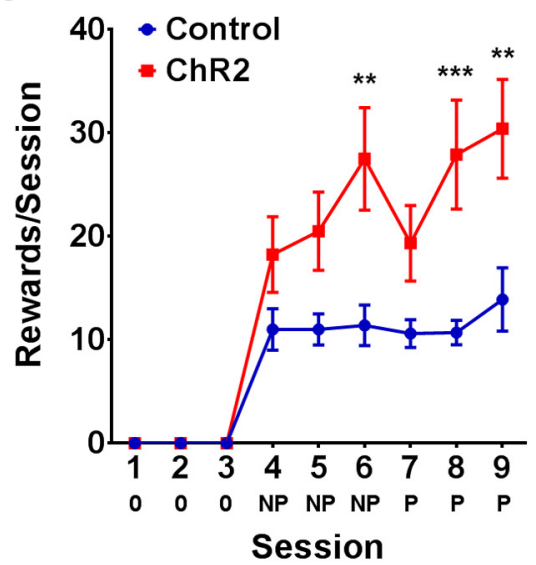

D

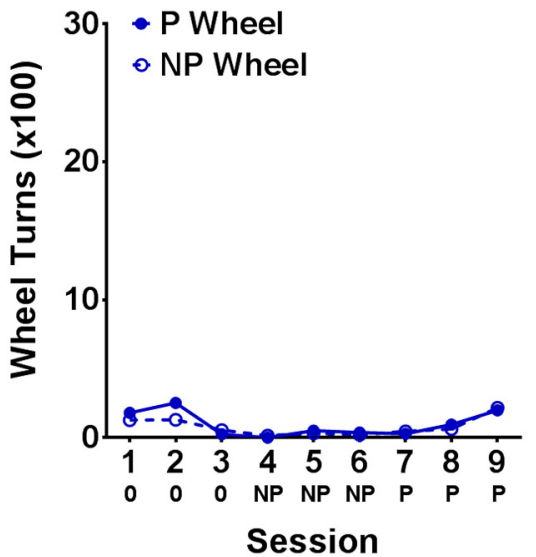

G

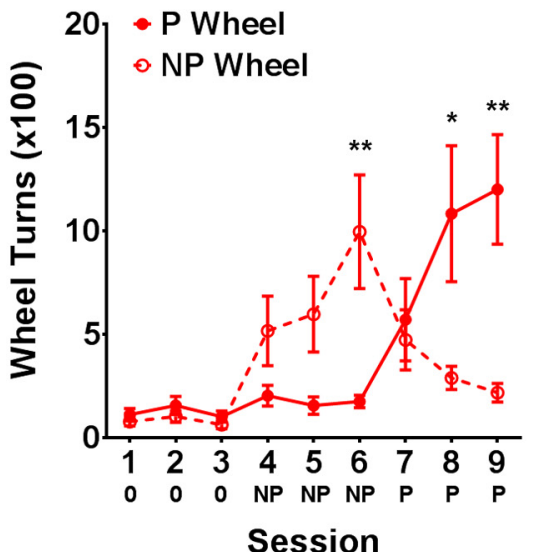

E

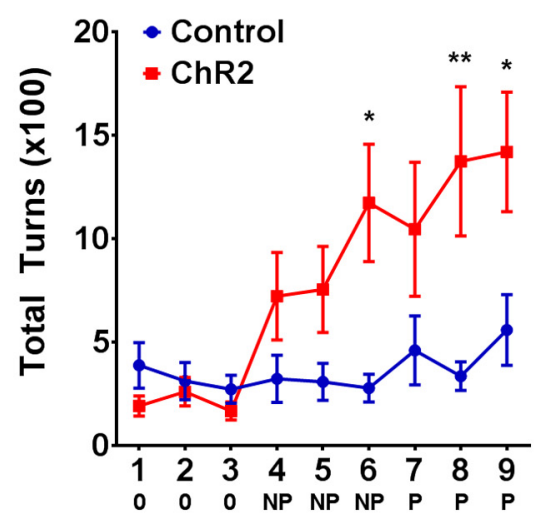

Session

H

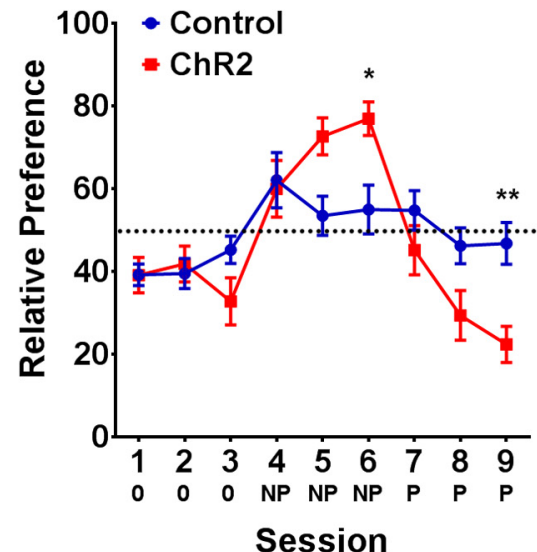

Figure 7. Optogenetic activation of dMHb neurons in vivo mediates primary reinforcement. $A$, Structure of the ICSS trials. Each $1 / 4$ turn of the active response wheel is scored as an event. When the reward condition is met, a $4 \mathrm{~s}$ train of $25 \mathrm{~ms}$ light pulses is delivered at a frequency of $20 \mathrm{~Hz}$, followed by a $2 \mathrm{~s} \mathrm{time} \mathrm{out} \mathrm{during} \mathrm{which} \mathrm{events} \mathrm{do} \mathrm{not} \mathrm{count} \mathrm{toward} \mathrm{a} \mathrm{reward.} \mathrm{Turns} \mathrm{of} \mathrm{the} \mathrm{inactive}$ wheel reset the event counter. B, Stepped fixed-ratio reinforcement structure of the ICSS sessions. Each 45 min session is initiated at a fixed event:reinforcement ratio of 1:1 until five rewards have been earned, then 5:1 until 10 total rewards have been earned, then $25: 1$ thereafter. $C$, Response data for a representative dMHb ${ }^{\text {ChR2 }}$ mouse across nine sessions; three sessions without laser stimulation (0), three sessions with laser stimulation evoked by turning the initially nonpreferred wheel (NP), and three crossover sessions of stimulation of the initially preferred wheel (P). D, Response data for a representative control mouse. $\boldsymbol{E}$, Summary of total wheel turns per session (sum of both wheels) for cohorts of dMHb ${ }^{\text {ChR2 }}$ and control mice. A trend toward increased wheel turning by $\mathrm{dMHb}^{\mathrm{ChR2}}$ mice relative to controls is observed on the first stimulated session (session 4) and is significant by session $6 .{ }^{* *} p<0.01$, significant difference between genotypes. ${ }^{*} p<0.05$, significant difference between genotypes. $\boldsymbol{F}$, Average number of rewards (light pulse trains) earned per session by dMHb ${ }^{\text {ChR2 }}$ and control mice. A dip is observed in the rewards earned on session 7 because of a large number of incorrect responses following the crossover of the rewarded side. The plateau observed in the control mice at $\sim 10$ rewards is due in part to the stepped FR schedule, in which additional effort is required for the 11 th and subsequent rewards. ${ }^{* * *} p<0.001$, significant difference between genotypes. ${ }^{* *} p<0.01$, significant difference between genotypes. $G$, Within-subjects comparison for mean wheel turns on the stimulated wheel (NP during sessions 4-6 and P during sessions 7-9) and nonstimulated wheel (P during sessions $4-6$ and NP during sessions 7-9) across the 6 stimulated sessions. The baseline sessions are not included in the analysis because no light stimulation was administered. During the first three stimulations on the NP wheel, a trend was observed toward greater turning of the reward-associated wheel in sessions 4 and 5, which became significant by session 6 . In the crossover sessions (sessions 7-9), mice rapidly shifted their response to the $\mathrm{P}$ wheel. ${ }^{* *} p<0.01$, significant difference between stimulation conditions. ${ }^{*} p<0.05$, significant difference between stimulation conditions. $\boldsymbol{H}$, Relative preference for the NP wheel across nine trials, expressed as NP wheel turns/total wheel turns $\times 100$. The dashed line indicates $50 \%$ or no preference. dMHb ${ }^{\mathrm{ChR2}}$ mice showed positive preference for NP wheel when it was the reward-associated wheel $(>50 \%)$ and negative preference $(<50 \%)$ for NP when it was inactive. Preference differences from control mice were significant by the last session with each reward-associated wheel (sessions 6 and 9). ${ }^{* *} p<0.01$, significant difference between genotypes. ${ }^{*} p<0.05$, significant difference between genotypes. $N=10$ control mice and $N=12 \mathrm{dMHb}{ }^{\text {ChR2 }}$ mice. 


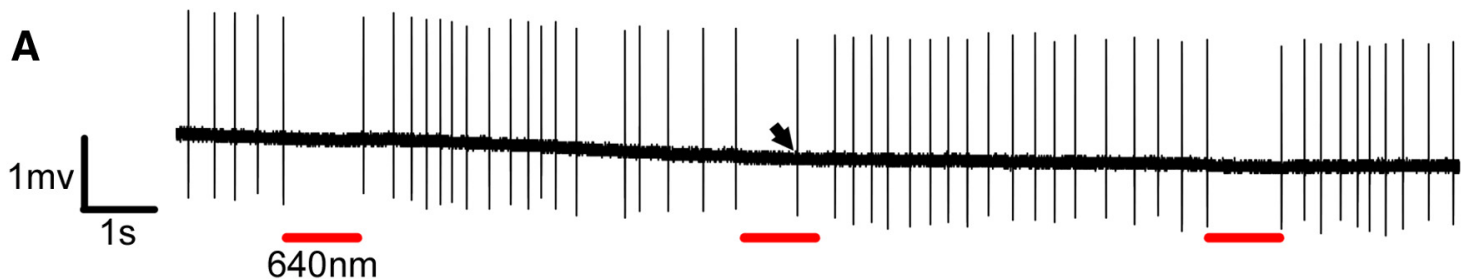

B

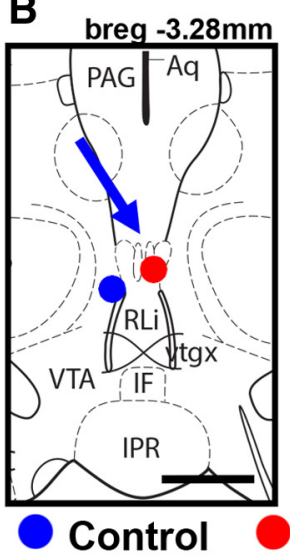

breg $-3.40 \mathrm{~mm}$

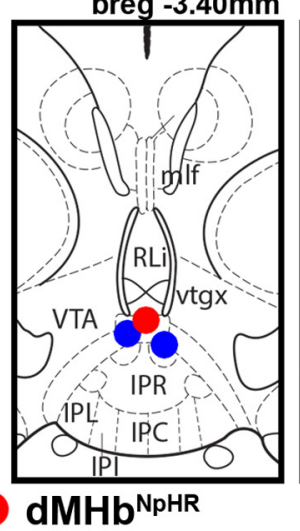

breg $-3.52 \mathrm{~mm}$

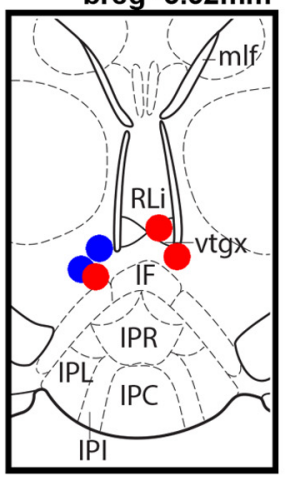

C

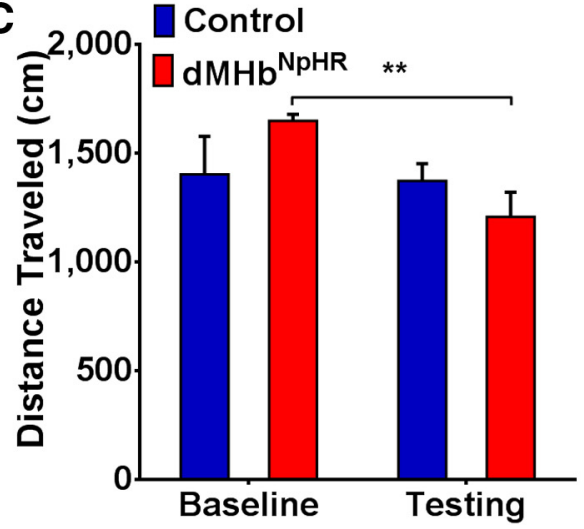

D

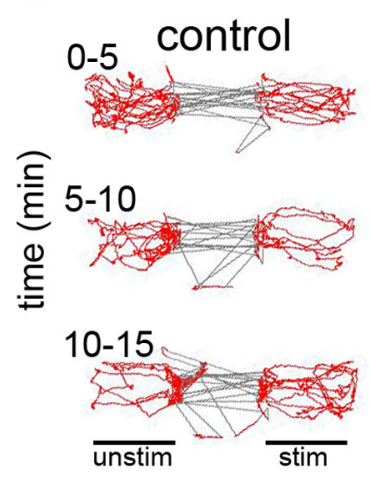

E

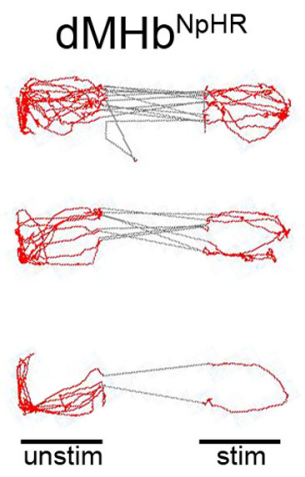

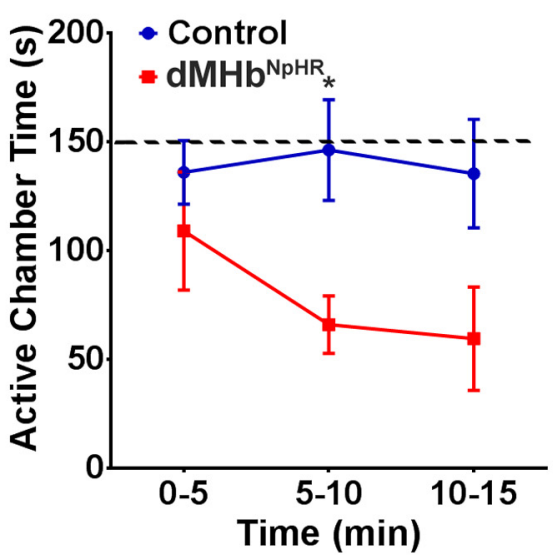

$\mathbf{F}$

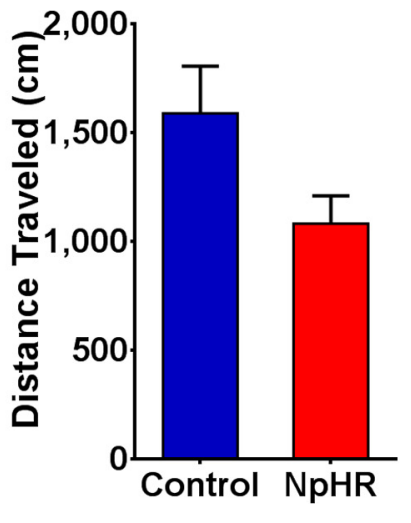

Figure 8. Inhibition of basal dMHb signaling to the IP induces acute place aversion. For in vivo experiments, a fiber optic was placed adjacent to the IP of control and dMHb ${ }^{\mathrm{NpHR}}$ mice, and $640 \mathrm{~nm}$ light was delivered when the mice appeared in one of the two main chambers of the three-compartment box. A, Loose-seal cell-attached recording of the dMHb in an acute slice preparation from a dMHb ${ }^{\mathrm{NpHR}}$ mouse. Irregular tonic firing at $\sim 3 \mathrm{~Hz}$ is observed at baseline. Application of $640 \mathrm{~nm}$ red light $\left(46 \mathrm{~mW} / \mathrm{mm}^{2}\right.$ ) for $1 \mathrm{~s}$ (red bars) produces effective silencing of action potentials. A single escaped action potential in the second period of inhibition is indicated by an arrow. Attempts at longer periods of continuous silencing were accompanied by more escape firing due to the strong pacemaker properties of these neurons (data not shown). B, Optical cannula placement in the IP. Single optical fibers ( $100 \mu \mathrm{m}$ diameter, $5 \mathrm{~mm}$ length) were surgically implanted and secured to the skull as described in Materials and Methods. The targeted coordinates for the cannula tip were as follows: rostrocaudal, bregma $-3.52 \mathrm{~mm}$; dorsoventral, $-4.29 \mathrm{~mm}$ ventral to lambda-bregma line; lateral, at midline. Blue represents the termini of the optical cannula tracks in control mice; red represents dMHb ${ }^{\mathrm{NpHR}}$ mice (on a standard anatomical map; Paxinos and Franklin, 2001). One track with an indeterminate end is depicted with an arrow. C, Open field locomotion of control and $\mathrm{dMHb}{ }^{\mathrm{NpHR}}$ mice. After a 10 min recording of baseline locomotion, the IP was illuminated intermittently for $10 \mathrm{~min}$, consisting of $30 \mathrm{~s}$ laser-on periods and $30 \mathrm{~s}$ laser-off periods $(640 \mathrm{~nm}, 8 \mathrm{~mW})$. A comparison of locomotion for the entire baseline and entire period of illumination is shown. Locomotion was not significantly different between the acute laser on and off periods in either genotype, but locomotion decreased over the course of testing in $\mathrm{dMHb}^{\mathrm{NpHR}}$ mice. ${ }^{* *} p<0.001$, significant difference between baseline and testing for $\mathrm{dMHb}^{\mathrm{NpHR}}$ mice. $\boldsymbol{D}$, Examples of locomotor activity recordings in the place preference/aversion assay for a single control and dMHb ${ }^{\mathrm{NpHR}}$ mouse. $\boldsymbol{E}$, Time spent in the laser-active compartment across three time intervals of the 15 min trial, demonstrating the development of aversion in $\mathrm{dMHb}^{\mathrm{NpHR}}$ mice. Dashed line indicates equal occupancy in the two large chambers. Significant aversion to the laser-active compartment was observed in $\mathrm{dMHb}^{\mathrm{NpHR}}$ mice after $5 \mathrm{~min} .{ }^{*} p<0.05$, significant difference between genotypes. $\boldsymbol{F}$, Distance traveled in the three-compartment box during preference/aversion assay. $N=4$ control and $N=6 \mathrm{dMHb}^{\mathrm{NPHR}}$ mice.

allele. Optogenetic inhibition of the dMHb was first tested in acute brain slice preparations. In cell-attached recordings, tonically firing $\mathrm{dMHb}$ neurons were effectively inhibited for short periods by continuous red light (Fig. 8A). However, frequent "escape" of the firing from inhibition was observed for light intervals exceeding a few seconds (arrow), presumably because of the strong pacemaker properties of these neurons. For this reason, we opted to target the fiber optic cannula to the terminals of the
$\mathrm{dMHb}$ fibers in the IPL rather than the dMHb cell bodies (Fig. 8B). Inhibition of action potential propagation by hyperpolarization of these terminals should be sufficient to prevent release of neurotransmitter signaling from the $\mathrm{dMHb}$ to the IP and does not require blocking the spontaneous firing of the $\mathrm{dMHb}$ neurons.

We first used open field locomotion to assess the effects of $\mathrm{dMHb}$ output inhibition in vivo in control and $\mathrm{dMHb}{ }^{\mathrm{NpHR}}$ mice. After a 10 min assessment of baseline locomotion, $\mathrm{dMHb}$ fibers 
in the IP were exposed to $10 \mathrm{~min}$ of intermittent periods of illumination with $640 \mathrm{~nm}$ light (30 s on, $30 \mathrm{~s}$ off). No difference in distance traveled was observed between the acute light on/off periods for either genotype $\left(F_{(1,8)}=0.097, p=0.76\right)$. However, there was an interaction between genotype and laser stimulation $\left(F_{(1,8)}=7.44, p=0.026\right)$, suggesting that the effect of the laser stimulation was different between control and $\mathrm{dMHb}^{\mathrm{NpHR}}$ mice. Post hoc analyses revealed that the $\mathrm{dMHb}^{\mathrm{NpHR}}$ mice showed a decrease in the cumulative distance traveled during the entire 10 min illumination trial compared with baseline $(p=0.0034$, Fig. $8 C)$.

To study the effects of dMHb inhibition on acute place preference/aversion, we used a three-chamber apparatus with a small central entry chamber, an active lateral chamber associated with continual laser illumination, and an inactive chamber without laser illumination. Because the laser was turned on or off by entry into the active or inactive lateral chambers, respectively, the small fraction of time spent in the middle entry compartment was assigned to whichever lateral chamber the subject most recently occupied. Examples of individual video activity records for one control and one $\mathrm{dMHb}^{\mathrm{NpHR}}$ mouse in a 15 min place preference/ aversion trial are shown in Figure $8 D$. During the initial 5 min of exploratory activity, the control and $\mathrm{dMHb}{ }^{\mathrm{NpHR}}$ mice exhibited approximately equal occupancy of the two compartments. However, over the subsequent $10 \mathrm{~min}$, the $\mathrm{dMHb}^{\mathrm{NpHR}}$ mouse developed aversion to the active chamber, whereas the control was unaffected.

Analysis of chamber occupancy over the course of the $15 \mathrm{~min}$ trial for the entire experimental group indicated a development of aversion to the stimulated chamber in $\mathrm{dMHb}{ }^{\mathrm{NpHR}}$ mice, whereas control mice consistently divided their time approximately equally between compartments $\left(F_{(1,9)}=5.50, p=0.044\right.$; Fig. $8 E$ ). The difference in chamber occupancy achieved significance between genotypes after $5 \mathrm{~min}(p=0.046)$. The $\mathrm{dMHb}^{\mathrm{NpHR}}$ mice also showed a trend toward less total distance traveled $\left(t_{(9)}=\right.$ $1.91, p=0.089$; Fig. $8 F$ ), which may result from the fact that they confined their movement to a smaller area for most of the trial.

Some caution is warranted in the interpretation of these optogenetic experiments because Syt6 ${ }^{\mathrm{Cre}}$ is expressed in brain regions other than the habenula, and thus the induced ChR2 or eNpHR3.0 expression is not confined to the dMHb. Like most optogenetic experiments, the specificity of the effects in this model depends both on the pattern of opsin expression and on locally targeted illumination. In the $\mathrm{dMHb}{ }^{\mathrm{ChR} 2}$ mice, cannulated dorsal to the $\mathrm{dMHb}$, the only ChR2-expressing cell bodies plausibly within the light path are in the habenula. However, Syt $6{ }^{\mathrm{Cre}}$ expressing cortical neurons project to thalamic nuclei that are ventral to the habenula, which lie $>1 \mathrm{~mm}$ from the cannula tip. Based on in vitro models for the transmission of $473 \mathrm{~nm}$ light in brain tissue (Aravanis et al., 2007), $<1 \%$ of the light intensity supplied to the $\mathrm{dMHb}$ should be received by these corticothalamic fibers. Although this calculation does not completely exclude in vivo stimulation of these fibers by a cannula placed above the $\mathrm{dMHb}$, this potential off-target effect is entirely circumvented by the IP inhibition experiments in $\mathrm{dMHb}{ }^{\mathrm{NpHR}}$ mice, in which the optical fiber bypasses the thalamus. Some ChR2-expressing neurons are also present in the $\mathrm{LHb}$ of $\mathrm{dMHb}{ }^{\mathrm{ChR} 2}$ mice and may receive some illumination from a cannula placed dorsal to the $\mathrm{dMHb}$. However, manipulation of LHb input to this area has been shown to have the opposite effects to those described here, with the activation of LHb fibers leading to aversion (Stamatakis and Stuber, 2012a). Thus, it is unlikely that either the reinforcement mediated by $\mathrm{dMHb}$ activation or the aversion mediated by
IP inhibition can be attributed to the off-target stimulation of $\mathrm{LHb}$ neurons or the inhibition of LHb terminal fibers in the tegmentum.

\section{Discussion}

The habenula has been implicated in the regulation of diverse behavioral functions, including learning and memory, reward, maternal behaviors, sleep, stress and affective states, and the behavioral effects of nicotine (Klemm, 2004; Lecourtier and Kelly, 2007). However, most prior studies have disrupted habenula function with lesions of the entire nucleus or the fasciculus retroflexus (FR), the output tract for the entire nucleus, and thus have not allowed the specific functions of $\mathrm{MHb}$ and $\mathrm{LHb}$, or their subnuclei, to be discerned. The distinct neurotransmitter properties of the $\mathrm{dMHb}$, characterized by the expression of the neuropeptide SP, and the specific projection of the $\mathrm{dMHb}$ to the lateral subnucleus of the IP, have been known for $>30$ years (Swanson and Cowan, 1979; Lecourtier and Kelly, 2007; Quina et al., 2009), yet no unique function has been assigned to this structure. To determine the role of the $\mathrm{dMHb}$ in behavior, we have created two mouse models: a developmental/genetic ablation model of the dMHb using Cre-mediated disruption of the Pou4f1 gene and optogenetic models in which we conditionally expressed channelrhodopsin or halorhodopsin in the dMHb. Together, data derived from these models show that the $\mathrm{dMHb}$ mediates exercise motivation, plays a role in the regulation of hedonic state, and supports primary reinforcement.

One of the most profound deficits observed in $\mathrm{dMHb}^{\mathrm{CKO}}$ mice is a reduction in voluntary WRA. A recent study in hamsters has shown that complete lesion of the FR also results in markedly decreased nocturnal WRA, as well as increased home cage locomotion (Paul et al., 2011). Here, using specific ablation of the $\mathrm{dMHb}$, we observed no difference between $\mathrm{dMHb}^{\mathrm{CKO}}$ and control mice in baseline locomotion in the open field enclosure (30 min, short-term) or in home cages (24 h, long-term). Direct comparison of these results must be made cautiously because of the different species used. However, it appears likely that specific $\mathrm{dMHb}$ lesions in mice affect the motivation to engage in WRA without the general effect on locomotion observed in FRlesioned hamsters, which may be attributable to the function of other habenula subnuclei. Thus, at least part of the motivation to engage in WRA can be assigned to the dMHb pathway.

WRA in rodents affects multiple physiological processes, ranging from physical activity and energy balance to motivation and regulation of hedonic state (Novak et al., 2012). Rats will lever-press for access to a running wheel or develop conditioned place preference in response to its presence (Iversen, 1993; Greenwood et al., 2011), and self-administration of cocaine is reduced in rats with access to running wheels, suggesting that wheel running is reinforcing and interacts with known reward mechanisms (Cosgrove et al., 2002). Access to a running wheel has also been shown to mitigate depression-like phenotypes in several rodent models, including learned helplessness, and the forced swim and tail suspension tests (Greenwood et al., 2003; Duman et al., 2008). The relevance of these findings to depression in humans is supported by clinical studies of major depression, in which structured exercise is one of the best-documented nonpharmacological therapeutic interventions (Blumenthal et al., 2007; Trivedi et al., 2011).

Despite normal baseline locomotion, $\mathrm{dMHb}{ }^{\mathrm{CKO}}$ mice also exhibited marked performance deficits in the accelerating rotarod compared with controls. Although the rotarod is frequently used to assess the function of motor circuits (Rustay et al., 2003), 
performance in this test also requires motivation, which is linked to affective state. Rotarod performance is impaired in rats exposed to chronic stress (Mizoguchi et al., 2002), a model of depression in rodents (Willner, 2005; Wiborg, 2013). Thus, together, the WRA and rotarod deficits in dMHb lesioned mice are likely to result from loss of motivation rather than a direct impairment of motor function. However, we cannot rule out some interaction between the subtle locomotor defects detected by the more sensitive gait analysis and balance beam tests and the motivation to engage in WRA.

$\mathrm{dMHb}^{\mathrm{CKO}}$ mice also show a reduced preference for the sucrose-sweetened drinking water normally preferred by control mice. A reduction in sucrose preference develops in chronically stressed rodents and is a model of anhedonia, the general loss of pleasure often exhibited by patients suffering from major depression (Willner et al., 1996; Willner, 2005). However, the dMHbCKO mice did not exhibit increased immobility time compared with control mice in the FST, another measure of depression-like states in rodents, suggesting that sucrose preference and the FST are mediated by distinct neural pathways. Both serotonin and opioids may be involved in the regulation of affective state by WRA (Greenwood et al., 2003; Duman et al., 2008). Future research will be needed to determine whether hedonic regulation by the $\mathrm{dMHb}$ intersects with serotonergic or opioid signaling pathways.

To determine whether $\mathrm{dMHb}$ activity could mediate reinforcement, we developed an optogenetic version of ICSS, which in its classic form is widely used to assess the ability of brain regions to support reinforcement (Carlezon and Chartoff, 2007). Conventional ICSS using stimulation electrodes has suggested that habenula stimulation may be reinforcing (Sutherland and Nakajima, 1981; Nakajima, 1984; Morissette and Boye, 2008), but it is difficult to stimulate specific neural populations, such as the $\mathrm{dMHb}$ with ICSS, or to distinguish effects on neurons from fibers of passage. In optogenetic ICSS, using a two responsewheel choice paradigm, $\mathrm{dMHb}{ }^{\mathrm{ChR} 2}$ mice show a strong preference for the wheel associated with laser stimulation and markedly increase wheel turning in response to this reinforcement. In contrast, inhibition of $\mathrm{dMHb}$ fiber terminals in the IP of $\mathrm{dMHb} \mathrm{b}^{\mathrm{NpHR}}$ mice leads to the rapid development of place aversion. These results, together with the loss of WRA motivation and sucrose preference, support a model in which the $\mathrm{dMHb}$ mediates signals with a positive valence. However, unlike the ICSS effects seen in classic studies of the medial forebrain bundle, the $\mathrm{dMHb}$ pathway is not obviously linked to dopaminergic (DA) systems. The output circuit of the $\mathrm{dMHb}$ is not fully known, but there is no evidence that the $\mathrm{dMHb}$ or its primary target, the lateral part of the IP, project to DA centers (Groenewegen et al., 1986). Thus, our sucrose preference data on $\mathrm{dMHb}{ }^{\mathrm{CKO}}$ mice are consistent with the observation that dopamine-deficient mice still develop sucrose preference (Cannon and Palmiter, 2003).

Recent work has shown that lesions of the specific septal inputs to the $\mathrm{dMHb}$ and $\mathrm{vMHb}$ (rather than the MHb nuclei themselves) show dissociable effects on fear conditioning and anxiety, respectively (Yamaguchi et al., 2013). We did not observe a significant difference between $\mathrm{dMHb}{ }^{\mathrm{CKO}}$ and control mice in open field center/periphery occupancy, one measure of anxiety, a result consistent with this study. In another recent study, Crerecombinase expressed from the gene locus Gpr151, an orphan receptor expressed in the $\mathrm{vMHb}$ and a subset of $\mathrm{LHb}$ neurons, was used to ablate neurons in these nuclei (Kobayashi et al., 2013), sparing the $\mathrm{dMHb}$. These mice exhibited a decrease in open field center occupancy, interpreted as increased anxiety. It will be interesting to determine the exact role of the specific $\mathrm{dMHb}$ and $\mathrm{vMHb}$ inputs, nuclei, and output pathways in fear and anxiety behaviors.

The finding here that the $\mathrm{dMHb}$ signaling has a positive valence contrasts markedly with recent findings on the role of the $\mathrm{LHb}$ in reward mechanisms. A subset of LHb neurons has recently been shown to mediate negative motivational values, including the absence of an expected reward and punishment, through inhibition of DA neurons (Jhou et al., 2009; Hikosaka, 2010; Bromberg-Martin and Hikosaka, 2011). Synaptic inputs to the LHb also are increased in learned helplessness, a model of depression (Li et al., 2011). The glutamatergic LHb neurons project to the GABAergic RMTg, which in turn inhibits DA rewardencoding neurons in the VTA (Barrot et al., 2012), and optogenetic activation of LHb inputs to this area elicits aversion/ behavioral avoidance (Lammel et al., 2012; Stamatakis and Stuber, 2012b).

This LHb-negative motivational system, however, cannot account for the entire role of the habenula in motivated behavior or the regulation of affective states. The existence of a parallel positive reinforcement system somewhere in the habenula can be inferred from prior reports, which have shown that the habenula supports ICSS reinforcement and that habenula lesions block ICSS of several brain regions (Morissette and Boye, 2008). Because the input and output circuitry of the LHb and $\mathrm{MHb}$ are quite distinct, as are the dorsal and ventral MHb (Quina et al., 2009; Hsu et al., 2013; Kobayashi et al., 2013), the function of each of these pathways should be considered separately. Our data demonstrate that some of the positive motivational properties of the habenula reside in the $\mathrm{dMHb}$, including exercise motivation and the maintenance of some aspects of hedonic state. In a pilot case, deep brain stimulation of the habenula has been shown to be therapeutic in depression (Sartorius et al., 2010). Although to date this has been interpreted in the context of the LHb-negative motivational system, the findings presented here indicate that the potential role of $\mathrm{dMHb}$ activity in clinical depression and the possible therapeutic manipulation of $\mathrm{dMHb}$ function should also be considered.

\section{References}

Aravanis AM, Wang LP, Zhang F, Meltzer LA, Mogri MZ, Schneider MB, Deisseroth K (2007) An optical neural interface: in vivo control of rodent motor cortex with integrated fiberoptic and optogenetic technology. J Neural Eng 4:S143-S156. CrossRef Medline

Barrot M, Sesack SR, Georges F, Pistis M, Hong S, Jhou TC (2012) Braking dopamine systems: a new GABA master structure for mesolimbic and nigrostriatal functions. J Neurosci 32:14094-14101. CrossRef Medline

Blumenthal JA, Babyak MA, Doraiswamy PM, Watkins L, Hoffman BM, Barbour KA, Herman S, Craighead WE, Brosse AL, Waugh R, Hinderliter A, Sherwood A (2007) Exercise and pharmacotherapy in the treatment of major depressive disorder. Psychosom Med 69:587-596. CrossRef Medline

Bromberg-Martin ES, Hikosaka O (2011) Lateral habenula neurons signal errors in the prediction of reward information. Nat Neurosci 14:12091216. CrossRef Medline

Brooks SP, Dunnett SB (2009) Tests to assess motor phenotype in mice: a user's guide. Nat Rev Neurosci 10:519-529. CrossRef Medline

Cannon CM, Palmiter RD (2003) Reward without dopamine. J Neurosci 23:10827-10831. Medline

Carlezon WA Jr, Chartoff EH (2007) Intracranial self-stimulation (ICSS) in rodents to study the neurobiology of motivation. Nat Protoc 2:29872995. CrossRef Medline

Clark PJ, Brzezinska WJ, Thomas MW, Ryzhenko NA, Toshkov SA, Rhodes JS (2008) Intact neurogenesis is required for benefits of exercise on spatial memory but not motor performance or contextual fear conditioning in C57BL/6J mice. Neuroscience 155:1048-1058. CrossRef Medline 
Contestabile A, Villani L, Fasolo A, Franzoni MF, Gribaudo L, Oktedalen O, Fonnum F (1987) Topography of cholinergic and substance $P$ pathways in the habenulo-interpeduncular system of the rat: an immunocytochemical and microchemical approach. Neuroscience 21:253-270. CrossRef Medline

Cosgrove KP, Hunter RG, Carroll ME (2002) Wheel-running attenuates intravenous cocaine self-administration in rats: sex differences. Pharmacol Biochem Behav 73:663-671. CrossRef Medline

Couch Y, Anthony DC, Dolgov O, Revischin A, Festoff B, Santos AI, Steinbusch HW, Strekalova T (2013) Microglial activation, increased TNF and SERT expression in the prefrontal cortex define stress-altered behaviour in mice susceptible to anhedonia. Brain Behav Immun 29:136-146. CrossRef Medline

Duman CH (2010) Models of depression. Vitam Horm 82:1-21. CrossRef Medline

Duman CH, Schlesinger L, Russell DS, Duman RS (2008) Voluntary exercise produces antidepressant and anxiolytic behavioral effects in mice. Brain Res 1199:148-158. CrossRef Medline

Eng SR, Lanier J, Fedtsova N, Turner EE (2004) Coordinated regulation of gene expression by Brn3a in developing sensory ganglia. Development 131:3859-3870. CrossRef Medline

Farley FW, Soriano P, Steffen LS, Dymecki SM (2000) Widespread recombinase expression using FLPeR (flipper) mice. Genesis 28:106-110. CrossRef Medline

Fedtsova NG, Turner EE (1995) Brn-3.0 Expression identifies early postmitotic CNS neurons and sensory neural precursors. Mech Dev 53:291304. CrossRef Medline

Gabriel AF, Marcus MA, Honig WM, Walenkamp GH, Joosten EA (2007) The CatWalk method: a detailed analysis of behavioral changes after acute inflammatory pain in the rat. J Neurosci Methods 163:9-16. CrossRef Medline

Görlich A, Antolin-Fontes B, Ables JL, Frahm S, Slimak MA, Dougherty JD, Ibañez-Tallon I (2013) Reexposure to nicotine during withdrawal increases the pacemaking activity of cholinergic habenular neurons. Proc Natl Acad Sci U S A 110:17077-17082. CrossRef Medline

Grady SR, Moretti M, Zoli M, Marks MJ, Zanardi A, Pucci L, Clementi F, Gotti C (2009) Rodent habenulo-interpeduncular pathway expresses a large variety of uncommon nAChR subtypes, but only the alpha3beta $4^{*}$ and alpha3beta3beta $4^{\star}$ subtypes mediate acetylcholine release. J Neurosci 29:2272-2282. CrossRef Medline

Greenwood BN, Foley TE, Day HE, Campisi J, Hammack SH, Campeau S, Maier SF, Fleshner M (2003) Freewheel running prevents learned helplessness/behavioral depression: role of dorsal raphe serotonergic neurons. J Neurosci 23:2889-2898. Medline

Greenwood BN, Foley TE, Le TV, Strong PV, Loughridge AB, Day HE, Fleshner M (2011) Long-term voluntary wheel running is rewarding and produces plasticity in the mesolimbic reward pathway. Behav Brain Res 217: 354-362. CrossRef Medline

Groenewegen HJ, Ahlenius S, Haber SN, Kowall NW, Nauta WJ (1986) Cytoarchitecture, fiber connections, and some histochemical aspects of the interpeduncular nucleus in the rat. J Comp Neurol 249:65-102. CrossRef Medline

Han S, Yu FH, Schwartz MD, Linton JD, Bosma MM, Hurley JB, Catterall WA, de la Iglesia $\mathrm{HO}$ (2012) $\mathrm{Na}(\mathrm{V}) 1.1$ channels are critical for intercellular communication in the suprachiasmatic nucleus and for normal circadian rhythms. Proc Natl Acad Sci U S A 109:E368-E377. CrossRef Medline

Hikosaka O (2010) The habenula: from stress evasion to value-based decision-making. Nat Rev Neurosci 11:503-513. CrossRef Medline

Hong S, Jhou TC, Smith M, Saleem KS, Hikosaka O (2011) Negative reward signals from the lateral habenula to dopamine neurons are mediated by rostromedial tegmental nucleus in primates. J Neurosci 31:11457-11471. CrossRef Medline

Hsu YW, Tempest L, Quina LA, Wei AD, Zeng H, Turner EE (2013) Medial habenula output circuit mediated by alpha5 nicotinic receptor-expressing GABAergic neurons in the interpeduncular nucleus. J Neurosci 33: 18022-18035. CrossRef Medline

Iversen IH (1993) Techniques for establishing schedules with wheel running as reinforcement in rats. J Exp Anal Behav 60:219-238. CrossRef Medline

Jhou TC, Fields HL, Baxter MG, Saper CB, Holland PC (2009) The rostromedial tegmental nucleus (RMTg), a GABAergic afferent to midbrain dopamine neurons, encodes aversive stimuli and inhibits motor responses. Neuron 61:786-800. CrossRef Medline

Kim U, Chang SY (2005) Dendritic morphology, local circuitry, and intrinsic electrophysiology of neurons in the rat medial and lateral habenular nuclei of the epithalamus. J Comp Neurol 483:236-250. CrossRef Medline

Klemm WR (2004) Habenular and interpeduncularis nuclei: shared components in multiple-function networks. Med Sci Monit 10:RA261RA273. Medline

Kobayashi Y, Sano Y, Vannoni E, Goto H, Suzuki H, Oba A, Kawasaki H, Kanba S, Lipp HP, Murphy NP, Wolfer DP, Itohara S (2013) Genetic dissection of medial habenula-interpeduncular nucleus pathway function in mice. Front Behav Neurosci 7:17. Medline

Lammel S, Lim BK, Ran C, Huang KW, Betley MJ, Tye KM, Deisseroth K, Malenka RC (2012) Input-specific control of reward and aversion in the ventral tegmental area. Nature 491:212-217. CrossRef Medline

Lecourtier L, Kelly PH (2007) A conductor hidden in the orchestra? Role of the habenular complex in monoamine transmission and cognition. Neurosci Biobehav Rev 31:658-672. CrossRef Medline

Leslie FM, Mojica CY, Reynaga DD (2013) Nicotinic receptors in addiction pathways. Mol Pharmacol 83:753-758. CrossRef Medline

Li B, Piriz J, Mirrione M, Chung C, Proulx CD, Schulz D, Henn F, Malinow R (2011) Synaptic potentiation onto habenula neurons in the learned helplessness model of depression. Nature 470:535-539. CrossRef Medline

Madisen L, Zwingman TA, Sunkin SM, Oh SW, Zariwala HA, Gu H, Ng LL, Palmiter RD, Hawrylycz MJ, Jones AR, Lein ES, Zeng H (2010) A robust and high-throughput Cre reporting and characterization system for the whole mouse brain. Nat Neurosci 13:133-140. CrossRef Medline

Madisen L, Mao T, Koch H, Zhuo JM, Berenyi A, Fujisawa S, Hsu YW, Garcia AJ 3rd, Gu X, Zanella S, Kidney J, Gu H, Mao Y, Hooks BM, Boyden ES, Buzsáki G, Ramirez JM, Jones AR, Svoboda K, Han X, et al. (2012) A toolbox of Cre-dependent optogenetic transgenic mice for light-induced activation and silencing. Nat Neurosci 15:793-802. CrossRef Medline

McEvilly RJ, Erkman L, Luo L, Sawchenko PE, Ryan AF, Rosenfeld MG (1996) Requirement for Brn-3.0 in differentiation and survival of sensory and motor neurons. Nature 384:574-577. CrossRef Medline

Mizoguchi K, Yuzurihara M, Ishige A, Sasaki H, Tabira T (2002) Chronic stress impairs rotarod performance in rats: implications for depressive state. Pharmacol Biochem Behav 71:79-84. CrossRef Medline

Morissette MC, Boye SM (2008) Electrolytic lesions of the habenula attenuate brain stimulation reward. Behav Brain Res 187:17-26. CrossRef Medline

Nakajima S (1984) Serotonergic mediation of habenular self-stimulation in the rat. Pharmacol Biochem Behav 20:859-862. CrossRef Medline

Novak CM, Burghardt PR, Levine JA (2012) The use of a running wheel to measure activity in rodents: relationship to energy balance, general activity, and reward. Neurosci Biobehav Rev 36:1001-1014. CrossRef Medline

Paul MJ, Indic P, Schwartz WJ (2011) A role for the habenula in the regulation of locomotor activity cycles. Eur J Neurosci 34:478-488. CrossRef Medline

Paxinos G, Franklin KBJ (2001) The mouse brain in stereotaxic coordinates, Ed 2. San Diego: Academic.

Quina LA, Pak W, Lanier J, Banwait P, Gratwick K, Liu Y, Velasquez T, O'Leary DD, Goulding M, Turner EE (2005) Brn3a-expressing retinal ganglion cells project specifically to thalamocortical and collicular visual pathways. J Neurosci 25:11595-11604. CrossRef Medline

Quina LA, Wang S, Ng L, Turner EE (2009) Brn3a and Nurr1 mediate a gene regulatory pathway for habenula development. J Neurosci 29:1430914322. CrossRef Medline

Ren J, Qin C, Hu F, Tan J, Qiu L, Zhao S, Feng G, Luo M (2011) Habenula "cholinergic" neurons co-release glutamate and acetylcholine and activate postsynaptic neurons via distinct transmission modes. Neuron 69: 445-452. CrossRef Medline

Rustay NR, Wahlsten D, Crabbe JC (2003) Influence of task parameters on rotarod performance and sensitivity to ethanol in mice. Behav Brain Res 141:237-249. CrossRef Medline

Salas R, Sturm R, Boulter J, De Biasi M (2009) Nicotinic receptors in the habenulo-interpeduncular system are necessary for nicotine withdrawal in mice. J Neurosci 29:3014-3018. CrossRef Medline

Sartorius A, Kiening KL, Kirsch P, von Gall CC, Haberkorn U, Unterberg AW, Henn FA, Meyer-Lindenberg A (2010) Remission of major depres- 
sion under deep brain stimulation of the lateral habenula in a therapyrefractory patient. Biol Psychiatry 67:e9-e11. CrossRef Medline

Sherwin CM (1998) Voluntary wheel running: a review and novel interpretation. Anim Behav 56:11-27. CrossRef Medline

Solberg LC, Horton TH, Turek FW (1999) Circadian rhythms and depression: effects of exercise in an animal model. Am J Physiol 276:R152-R161. Medline

Stamatakis AM, Stuber GD (2012a) Activation of lateral habenula inputs to the ventral midbrain promotes behavioral avoidance. Nat Neurosci 15: 1105-1107. CrossRef Medline

Stamatakis AM, Stuber GD (2012b) Optogenetic strategies to dissect the neural circuits that underlie reward and addiction. Cold Spring Harb Perspect Med 2:a011924. CrossRef Medline

Strekalova T, Spanagel R, Bartsch D, Henn FA, Gass P (2004) Stressinduced anhedonia in mice is associated with deficits in forced swimming and exploration. Neuropsychopharmacology 29:2007-2017. CrossRef Medline

Sutherland RJ, Nakajima S (1981) Self-stimulation of the habenular complex in the rat. J Comp Physiol Psychol 95:781-791. CrossRef Medline
Swanson LW, Cowan WM (1979) The connections of the septal region in the rat. J Comp Neurol 186:621-655. CrossRef Medline

Trivedi MH, Greer TL, Church TS, Carmody TJ, Grannemann BD, Galper DI, Dunn AL, Earnest CP, Sunderajan P, Henley SS, Blair SN (2011) Exercise as an augmentation treatment for nonremitted major depressive disorder: a randomized, parallel dose comparison. J Clin Psychiatry 72: 677-684. CrossRef Medline

Wiborg O (2013) Chronic mild stress for modeling anhedonia. Cell Tissue Res 354:155-169. CrossRef Medline

Willner P (2005) Chronic mild stress (CMS) revisited: consistency and behavioural-neurobiological concordance in the effects of CMS. Neuropsychobiology 52:90-110. CrossRef Medline

Willner P, Moreau JL, Nielsen CK, Papp M, Sluzewska A (1996) Decreased hedonic responsiveness following chronic mild stress is not secondary to loss of body weight. Physiol Behav 60:129-134. CrossRef Medline

Yamaguchi T, Danjo T, Pastan I, Hikida T, Nakanishi S (2013) Distinct roles of segregated transmission of the septo-habenular pathway in anxiety and fear. Neuron 78:537-544. CrossRef Medline 